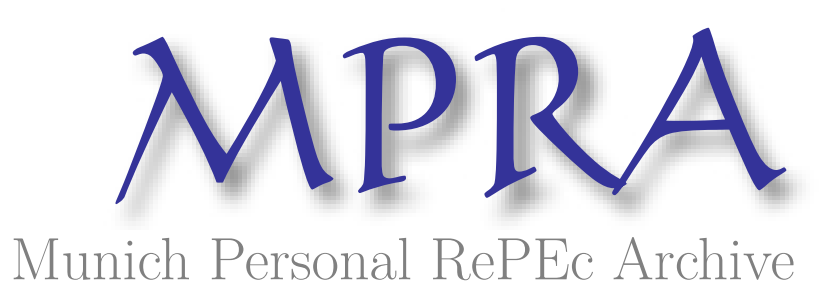

\title{
Inequality, Uncertainty, and Redistribution
}

\author{
Machado, Fabiana \\ Inter-American Development Bank
}

11 September 2011

Online at https://mpra.ub.uni-muenchen.de/35665/

MPRA Paper No. 35665, posted 01 Jan 2012 00:26 UTC 


\title{
Inequality, Uncertainty and Redistribution.*
}

\author{
Fabiana Machado ${ }^{\dagger}$
}

September, 2011

\begin{abstract}
For centuries it has been believed that the extension of the franchise in unequal societies would lead to relatively high levels of redistribution. According to international rankings, however, among the fourteen most unequal countries in the world, nine have been democratic for at least the past fourteen years. A prerequisite for the adoption of redistributive policies is that there be elected representatives who are either committed to or who have an incentive to advocate for such policies. The prospects of such an outcome depend not only on candidates personal policy preferences and motivations, but also how they are perceived by voters. One important feature shared by highly unequal democracies is that they tend to be relatively young, with many new parties and candidates in the political scene. This means elections occur under a high degree of uncertainty about critical information voters need to chose their delegates. Thus, in this paper I develop a model of elections as a game of incomplete information to explore how uncertainty, candidates' motivation (policy vs. office), and beliefs about their ideological inclinations affect what policy interests are likely to be represented in the political process. I explore the model's assumptions and outcomes empirically using individual level data for each presidential election in Brazil since democratization.
\end{abstract}

\footnotetext{
*I would like to thank Mark Fey, Gretchen Helmke, James Johnson, and Bing Powell for valuable discussions and advice. I am also grateful to participants at the Watson Seminar at the University of Rochester, the Econnet at the IADB, and at the 2009 Midwest Political Science Association Meeting for their helpful comments and suggestions at an earlier version of this paper.

${ }^{\dagger}$ Inter-American Development Bank
} 


\section{Introduction}

For centuries it has been believed that the extension of the franchise in unequal societies would lead to high levels of redistribution. Benjamin Constant (1767-1830), for example, wrote:

Notice that the necessary aim of those without property is to obtain some: all the means which you grant them are sure to be used for this purpose. If, to the freedom to use their talents and industry, which you owe them, you add political rights, which you do not owe them, these rights, in the hands of the greatest number, will inevitably serve to encroach upon property. (Constant, 1988, pg. 215).

Marx expresses similar expectations in Surveys from Exile (Marx, 1973), and, more recently, a number of authors have formalized the idea. Among the most famous studies is the work by Meltzer and Richard that shows how majority rule would lead to high levels of redistribution in societies where the income of the median voter lies well below that of the average voter. Under high inequality, a uniform tax schedule with equal distribution of the proceedings among individuals would benefit all those earning less than the average income. Thus redistribution would be a winning policy platform.

In reality, however, the extension of political rights in unequal societies does not necessarily lead to high levels of redistribution. If we consider the latest ranking of countries by the United Nations, we find that among the most unequal ones, a considerable share has been considered democratic for more than a decade ${ }^{1}$.

Democracies are representative forms of government. This means citizens need to choose individuals to represent their interests and to whom policy decisions will be delegated. Thus, elections are a fundamental stage in the democratic political process and the main instruments for citizens to affect political decisions (Powell, 2000). So the crucial question is: under what conditions would we expect candidates who are either committed to or who have an incentive to advocate for redistribution to be elected?

\footnotetext{
${ }^{1}$ Namibia, Lesotho, Botswana, Bolivia, Colombia, Brazil, Paraguay, South Africa and Chile are among the top fourteen most unequal countries in the world and have received a polity score of 6 or higher for at least the past fifteen years. The polity score varies from -10 (very undemocratic) to 10 (very democratic).
} 
To answer this question I develop a model of elections as a game of incomplete information and explore how uncertainty, candidates' motivation (policy vs. office), and voters' beliefs about candidate's ideological inclinations affect what policy interests are likely to be represented in the political process. I characterize all pure strategy equilibria to gain insight into the conditions leading to both high and low redistribution, and explore some of the empirical implications of the model using individual level data from Brazil.

As pointed by Duggan (2000) the downsian model of elections, which is the basis of most models trying to explain levels of redistribution, relies on two very strong assumptions. The first is that politicians have no personal policy preferences and all they care about is implementing whatever policies would get them elected. Second, given this office motivation, they can make credible commitments to these policies during campaigns. Similar to Duggan (2000), I model politicians with policy preferences just like voters, and allow them to be motivated by both office and policy.

When politicians care about what policies end up being implemented, they may announce the "median voter" platform to win votes, but lack credible commitment to implement it. Once in office, candidates need to weight the benefits of remaining in office against the costs of implementing policies they might dislike. It is thus important to explicitly model candidate motivation.

If candidates care solely about holding office, they would be inclined to implement policies favored by a majority, even if, based on their own personal convictions, they actually oppose them. For other candidates, however, one of the biggest benefits of holding office is indeed the opportunity to implement policies they favor, and get rid of those they oppose. Thus, in order to assess candidates's incentives, voters need to consider their motivations in addition to their ideological inclinations. The next important question then is what do voters know about candidates personal policy preferences?

One important shared characteristic among the most unequal democracies today is that they are relatively new democracies. This means new political parties and candidates emerge with some frequency in the political scene, making it difficult for voters to know their particular policy inclinations. Thus voters make their choices during elections under a great deal of uncertainty about crucial information. And this uncertainty should be at the heart of any model of elections. 
This lack of information on the part of voters is usually formalized based on the citizen-candidate model of Osborne and Slivinski (1996). The assumption is that candidates are randomly drawn from the pool of voters, whose distribution of preferences is known. Unlike this conventional approach, I model candidates by type - whether they are left, center or right leaning - without assuming that the distribution of preferences across candidates mirrors that of voters.

The reason for relaxing this assumption is that the fact that a majority of voters favor certain policies, does not mean a majority of politicians do too. In most countries being a viable candidate is a very expensive enterprise. Given that redistributive policies take away from the rich and give out to the poor, these costs can restrict the entry of candidates who are committed to the cause of the poor.

Based on these assumptions and the set up described in detail in the next section, I characterize three pure-strategy equilibria that provide insight into our main question. To preview the main results, I find that low levels of redistribution under high inequality are supported by the belief that candidates who care about the welfare of the poor are rare. In other words, the more poor voters are skeptical about having candidates truly representing their interests, the more likely is low redistribution to persist. As pointed by Robinson (2009) one important obstacle to lowering inequality in developing countries is the lack of political contenders who actually favor redistribution.

I also find that the often observed pattern of poor voters reelecting non-redistributive incumbents is not necessarily a sign that the poor do not care about policy or that they are selling their votes or being irrational or ignorant in assessing candidates' policy positions. Even under the assumption that they are as capable as any other voter to evaluate policy and update beliefs about politicians preferences, such an outcome can occur.

The paper is divided into four parts. In the next section I introduce and solve the model. I then explore the empirical plausibility of the conditions found to support an equilibrium of low redistribution under high inequality. I base this analysis on individual level data collected during presidential election years in Brazil. I conclude with a summary of results and a brief discussion. 


\section{The Model}

I model a polity with three groups of voters, $i=\{p, m, r\}$, where $p$ stands for poor, $m$ for middle and $r$ for rich, and three types of candidates, $t=\{L, C, R\}$, where $L$ stands for left, $C$ for center, and $R$ for right. I consider a unidimensional policy space where policies, denoted by $x$, can take the following values: $x \in\left\{0, \frac{1}{2}, 1\right\}$. Each member of a group of voters share the same ideal policy denoted by $\tilde{x}_{i}$. Each type of candidate is associated with an ideal policy that I identify by $\tilde{x}_{t}$. These are given by:

- $\tilde{x}_{L}=\tilde{x}_{p}=0$

- $\tilde{x}_{C}=\tilde{x}_{m}=\frac{1}{2}$

- $\tilde{x}_{R}=\tilde{x}_{r}=1$

I model a two-period game of incomplete information where voters know their own types, but do not know the candidates' types. All players share a common prior distribution of these types. This is given by $p_{L}>0, p_{C}>0$ and $p_{R}>0$, denoting the probabilities of a candidate being at the left, the center or the right of the ideological space, and where $\sum p_{t}=1$. Candidates are assumed to have full information. They know their own type and those of the voters. The distribution of voters in the population is known to all players and is given by $p_{p}, p_{m}$ and $p_{r}$, where $\sum p_{i}=1$.

It is assumed the group of poor voters form a majority in the population, that is $p_{p}>\frac{1}{2}$, as is the case in most unequal countries. Furthermore, I assume that they all vote in each election.

The utility of candidates is as a function of their preferred policies $\left(\tilde{x}_{t}\right)$ and the extent to which they are office oriented (Calvert, 1985; Duggan and Fey, 2005). This is captured by the term $w \geq 0$. When $w=0$ candidates are said to be purely policy oriented. As $w$ increases the value of office grows relative to that of policy and candidates become increasingly office oriented. Candidates' utilities are given by:

$$
\begin{gathered}
U_{t}^{e}(x)=-\left(x-\tilde{x}_{t}\right)^{2}+w \\
U_{t}^{n e}(x)=-\left(x-\tilde{x}_{t}\right)^{2} .
\end{gathered}
$$


where $e$ stands for "elected" and ne stands for "non-elected". In the model, candidates and voters have Euclidean preferences for policy. Voters' utilities are simply a function of policy, and can be written as:

$$
U_{i}(x)=-\left(x-\tilde{x}_{i}\right)^{2}
$$

Candidates can be reelected once, that is, they do not serve more than two terms. The game sequence can be described as follows.

(1) Nature draws the first incumbent ${ }^{2}$;

(2) Incumbent implements policy $x^{1}$, where the superscript 1 denotes the first period;

(3) Voters observe $x^{1}$ and, whenever possible, update their beliefs about the incumbent's type via Bayes' Rule.

(4) Nature draws a challenger;

(5) Voters cast their votes;

(6) Winner becomes the incumbent in the second period and implements $x^{2}$. Game ends.

Candidates strategies consist of a pair of policies denoted $s_{t}=\left(x_{t}^{1}, x_{t}^{2}\right)$ chosen to maximize their expected utilities as incumbents in the first and second periods, given the strategies of the other players. Let $S=\left(s_{L}, s_{C}, s_{R}\right)$.

Candidates' expected utility can be written as follows:

$$
E U_{t}\left(s_{t}, s_{-t}\right)=U_{t}^{e}\left(x_{t}^{1}\right)+\Gamma\left(\gamma_{i}\right)\left[U_{t}^{e}\left(x_{t}^{2}\right)\right]+\left(1-\Gamma\left(\gamma_{i}\right)\right) \sum p_{t}\left[U_{t}^{n e}\left(x_{t}^{2}\right)\right]
$$

where $\Gamma$ is a function that maps voters' strategies denoted by $\gamma_{i}\left(x^{1}\right)$ (defined below) to a probability of the incumbent being reelected. Let $\sigma=\left(\gamma_{p}, \gamma_{m}, \gamma_{r}\right)$, then $\Gamma: \sigma \rightarrow[0,1]$.

Voters' strategies consist of deciding whether to vote for the incumbent, $\gamma_{i}\left(x^{1}\right)=1$, or the challenger, $\gamma_{i}\left(x^{1}\right)=0$. If indifferent, a voter votes for the incumbent with probability $\frac{1}{2}$.

\footnotetext{
${ }^{2}$ Since in the first period voters have no information about candidates' types, it is assumed they "flip a coin" in deciding who to vote for.
} 
In deciding who to vote for, voters compare their expected utility from reelecting the incumbent (I) with that of electing the challenger $(\mathrm{Ch})$ instead. These expected utilities are given by:

$$
\begin{aligned}
E U_{i}(I) & =\sum \mu_{\left(t \mid x^{1}, S\right)}\left[U_{i}\left(x_{t}^{2}\right)\right], \text { and } \\
E U_{i}(C h) & =\sum p_{t}\left[U_{i}\left(x_{t}^{2}\right)\right]
\end{aligned}
$$

where $\mu_{\left(t \mid x^{1}, S\right)}$ is the updated probability that the incumbent is of type $t$ given the policy she implemented in her first term. This probability is updated whenever possible following Bayes' Rule.

Given the features of the model, I use the Perfect Bayesian Equilibrium concept. A complete characterization of such equilibria includes a full description of beliefs, that is, not only those updated beliefs following equilibrium strategies but also those following off-the-equilibrium-path actions. Given the latter can take numerous forms generating a multiplicity of equilibria, I apply the divinity refinement.

$\gamma_{i}\left(x^{1}\right)$ is a step function, defined as follows:

$$
\begin{aligned}
& \gamma_{i}\left(x^{1}\right)=1 \quad \text { if } \quad E U_{i}(I)>E U_{i}(C h) \\
& \gamma_{i}\left(x^{1}\right)=0 \quad \text { if } \quad E U_{i}(I)<E U_{i}(C h) \\
& \gamma_{i}\left(x^{1}\right)=\frac{1}{2} \quad \text { if } \quad E U_{i}(I)=E U_{i}(C h)
\end{aligned}
$$

$\Gamma\left(\gamma_{i}\right)$ is simply a function that weights each of the groups' strategies by the groups' sizes to determine whether the incumbent gets reelected or not.

Clearly, voters should consider how the other players vote in making their final decisions. Given the assumption that the poor form a majority of the electorate and always turn out to vote, unless they are indifferent between the two contenders, their vote is decisive and strategic voting does not play a role. 


\section{Results}

The model yields three different pure strategy equilibria. In the first equilibrium, candidates value office to a relatively high extent. They find it thus profitable to choose the policy that pleases the majority of poor voters in the first period to secure a chance at reelection. As a result voters are indifferent between the incumbent and the challenger.

In the second equilibrium, the value of office is low enough to make the right-wing candidate choose her ideal policy in the first period even if that means no reelection. It is, however, still profitable for the moderate type to mimic the left candidate and implement the ideal policy of the poor. Voters, in turn, reelect only incumbents who implement their preferred policy in their first term.

Finally, for relatively low values of office we get an equilibrium where each candidate implements their ideal policy, revealing their exact type. Both the left and the moderate types get reelected. That is, even with full information about the incumbent's type, poor voters reelect a non-left representative.

Proposition 1: If $w>2-p_{L}-\frac{p_{C}}{4}$, and $p_{R}<\frac{1}{4}\left(1-p_{C}\right)$ there exists a unique Perfect Bayesian Equilibrium where:

- candidates play:

$$
S^{*}=\left(\left(x_{L}^{1}=0, x_{L}^{2}=0\right),\left(x_{C}^{1}=0, x_{C}^{2}=\frac{1}{2}\right),\left(x_{R}^{1}=0, x_{R}^{2}=1\right)\right) ;
$$

- voters' beliefs are:

$$
\mu_{L \mid 0, S^{*}}=p_{L}, \mu_{C \mid 0, S^{*}}=p_{C}, \mu_{R \mid 0, S^{*}}=p_{R}, \mu_{R \mid\left\{\frac{1}{2}, 1\right\}, S^{*}}=1 ;
$$

- voters choose: $\gamma_{i}(0)=\frac{1}{2}$ for all $i$, and $\gamma_{p}\left(\frac{1}{2}\right)=\gamma_{p}(1)=0$.

The first equilibrium is described in Proposition 1. Because every incumbent decides to implement the same policy, voters cannot learn about their ideological inclinations, making them indifferent between the incumbent and the challenger during elections. This equilibrium is supported by two conditions. First, candidates are sufficiently office oriented, as opposed to caring 
mainly about policy. That makes it profitable for both the right and moderate type to concede on policy - by implementing a leftist policy in the first period - for a chance to remain in office for a second term.

The second condition is the shared belief that a right type is relatively rare. This means the expected utility from an unknown challenger is higher than that expected from the moderate type. Thus poor voters do not reelect incumbents implementing $x^{1}=\frac{1}{2}$, guaranteeing $C$ has no incentive to deviate.

Another possible equilibrium (stated in Proposition 2) is one where only the left and the moderate candidates choose the preferred policy of the poor in the first period and get reelected. The Right candidate plays her ideal policy in both periods, but does not remain in power for a second term.

Proposition 2: If $\frac{1}{4}\left(\frac{p_{C}}{p_{C}+p_{L}}-p_{C}\right)<p_{R}<\frac{1}{4}\left(1-p_{C}\right)$ and $\frac{p_{C}}{4}<w<1-p_{L}-\frac{p_{C}}{4}$, there exists a unique separating Perfect Bayesian Equilibrium where:

- candidates play:

$$
S^{*}=\left(\left(x_{L}^{1}=0, x_{L}^{2}=0\right),\left(x_{C}^{1}=0, x_{C}^{2}=\frac{1}{2}\right),\left(x_{R}^{1}=1, x_{R}^{2}=1\right)\right) ;
$$

- voters' beliefs are':

$$
\mu_{L \mid 0, S^{*}}=\frac{p_{L}}{p_{C}+p_{L}}, \mu_{C \mid 0, S^{*}}=\frac{p_{C}}{p_{C}+p_{L}}, \mu_{R \mid\left\{\frac{1}{2}, 1\right\}, S^{*}}=1
$$

- voters choose: $\gamma_{p}(0)=1$ and $\gamma_{p}\left(\frac{1}{2}\right)=\gamma_{p}(1)=0$.

Two conditions need to be satisfied to support this equilibrium. First, the probability of a right type needs to be relatively low, but not too low. The upper bound on $p_{R}$ guarantees that poor voters would not reelect an incumbent who implements $x^{1}=\frac{1}{2}$, which would encourage $C$ to deviate. The lower bound guarantees that poor voters reelect the incumbent after observing the leftist policy, since they know there is a chance the incumbent is a moderate and will thus implement $x^{2}=\frac{1}{2}$.

The second condition specifies a range on the value candidates place on holding office. The intuition for the upper bound is that the Right candidate needs to care enough about policy 
relative to office in order to prefer her ideal point as opposed to deviating to get votes. The lower bound plays the opposite role with respect to $C$. Since $C$ is not implementing her ideal policy, she needs to care enough about office not to have an incentive to deviate to her preferred policy outcome.

Finally, in a third possible equilibrium (stated in Proposition 3) each type implements her own ideal policy in both periods. Thus after observing an incumbent in office, voters know her ideological preferences for certain. Even then, both left and moderates get reelected.

Proposition 3: If $w<\frac{1}{4}\left(1-p_{C}\right)-p_{L}$, there exists a unique separating Perfect Bayesian Equilibrium where:

- candidates play:

$$
S^{*}=\left(\left(x_{L}^{1}=0, x_{L}^{2}=0\right),\left(x_{C}^{1}=\frac{1}{2}, x_{C}^{2}=\frac{1}{2}\right),\left(x_{R}^{1}=1, x_{R}^{2}=1\right)\right) ;
$$

- voters' beliefs are:

$$
\mu_{L \mid 0, S^{*}}=1, \mu_{C \mid \frac{1}{2}, S^{*}}=1, \mu_{R \mid 1, S^{*}}=1 ;
$$

- voters choose $\gamma_{p}(0)=\gamma_{p}\left(\frac{1}{2}\right)=1$, and $\gamma_{p}(1)=0$.

The condition supporting this equilibrium is that candidates be sufficiently policy oriented. This guarantees that the right type has no incentive to deviate to a moderate policy in the first period to get reelected. A corollary of this condition is that the prior probability of a left type be relatively small. This leads voters to expect policies closer to the right from an unknown challenger, thus leading the poor to reelect a moderate. These expectations also play a role in the utility of the right type. Not getting reelected is not too bad if the chances that another right candidate will come to power and implement her preferred policy are high.

Figure 1 displays the values of the parameters supporting the equilibria described in Propositions 1 and 3. Note that the equilibrium described in proposition 2 - not displayed in the Figure - holds for the same probability distribution of types in equilibrium 1, except that the values of office lie between those of proposition 1 and 3 .

In general, Proposition 3 is the one that most closely reflect the reality in many unequal democracies. Politicians who are genuinely interested in the welfare of the worse-off and able to imple- 
ment redistributive policies are relatively rare. As a consequence, poor voters are likely to settle for policies further away from their ideal with the overall result being possibly long spells of low redistribution. Interestingly, however, even in the presence of uncertainty, the lack of redistribution in unequal societies is not necessarily a consequence of parties being office oriented and caring thus little about policy (this would actually lead to more rather than less redistribution).

\section{Extensions}

How far to the right?

Given that it can be rational for the poor to reelect non-leftist incumbents even under full information about their policy preferences, a natural question that arises is how far to the right an incumbent can be and still get reelected. The answer is stated in Proposition 4.

Let $\tilde{x}_{C}=a$, where $a \in(0,1)$. I can restate Proposition 3 as follows:

Proposition 4: If $w<(1-a)^{2}\left(1-p_{C}\right)-p_{L}$, there exists a separating Perfect Bayesian Equilibrium where:

- candidates play:

$$
S^{*}=\left(\left(x_{L}^{1}=0, x_{L}^{2}=0\right),\left(x_{C}^{1}=a, x_{C}^{2}=a\right),\left(x_{R}^{1}=1, x_{R}^{2}=1\right)\right)
$$

- voters' beliefs are:

$$
\mu_{L \mid 0, S^{*}}=\mu_{C \mid a, S^{*}}=\mu_{R \mid 1, S^{*}}=1 ;
$$

- voters choose $\gamma_{p}(0)=\gamma_{p}(a)=1$, and $\gamma_{p}(1)=0$.

The conditions supporting an equilibrium where poor voters reelect a "moderate" incumbent becomes increasingly restrictive as her ideal policy becomes closer to the rightmost policy. As $a \rightarrow 1, p_{L} \rightarrow 0$ and $w \rightarrow 0$. That is, the more players perceive a redistributive type as a rare type, and the more candidates care about policy relative to office, the more poor voters would be willing to reelect an incumbent who does not redistribute much. Again, this holds with full knowledge of the incumbent's policy preferences. 


\section{Risk neutrality}

So far I have assumed concave utilities over policies. That is, players are risk averse. It is indeed common to attribute risk aversion to individuals, in particular poor ones ${ }^{3}$. Thus it is interesting to understand what role this assumption plays in the equilibria discussed so far. In order to do it I characterize similar equilibria under the assumption of risk neutrality drawing attention to differences between them. Under this alternative assumption, candidates' utilities are given by ${ }^{4}$ :

$$
\begin{gathered}
U_{t}^{e}(x)=-\left|x-\tilde{x}_{t}\right|+w, \\
U_{t}^{n e}(x)=-\left|x-\tilde{x}_{t}\right|
\end{gathered}
$$

and voters' utilities by:

$$
U_{i}(x)=-\left|x-\tilde{x}_{i}\right|
$$

I begin by examining the semi-pooling equilibrium, where all candidates choose the leftmost policy in their first term and their ideal policies in the second term. The conditions assuming the poor are risk neutral are stated in Proposition 5. We notice that the equilibrium holds with less restrictive conditions than when risk aversion is assumed. In particular, we see that the value of office can be smaller than that stated in Proposition 1, while the shared probability of a right type can be higher.

Proposition 5: If $w>2-p_{L}-\frac{p_{C}}{2}$, and $p_{R}<\frac{1}{2}\left(1-p_{C}\right)$ there exists a Perfect Bayesian Equilibrium where:

- candidates play:

$$
S^{*}=\left(\left(x_{L}^{1}=0, x_{L}^{2}=0\right),\left(x_{C}^{1}=0, x_{C}^{2}=\frac{1}{2}\right),\left(x_{R}^{1}=0, x_{R}^{2}=1\right)\right) ;
$$

\footnotetext{
${ }^{3}$ Interesting experiments were run in Canada and Peru to capture the degree to which the poor are risk averse and have short term horizons. For results see Engle-Warnick et al. (2006) and Eckel et al. (2004)

${ }^{4}$ Notice that while both the poor and rich are risk neutral in this case, moderates are not. Given their central position their utility function is tent-shaped
} 
- voters' beliefs are:

$$
\mu_{L \mid 0, S^{*}}=p_{L}, \mu_{C \mid 0, S^{*}}=p_{C}, \mu_{R \mid 0, S^{*}}=p_{R}, \mu_{C \mid \frac{1}{2}, S^{*}}=\mu_{R \mid 1, S^{*}}=1 ;
$$

- voters choose: $\gamma_{i}(0)=\frac{1}{2}$ for all $i$, and $\gamma_{p}\left(\frac{1}{2}\right)=\gamma_{p}(1)=0$.

Consider now the equilibrium where the moderate pools with $L$ in the first period - choosing $x^{1}=0$ - and $R$ plays her ideal policy in both periods. As stated in Proposition 6, under risk neutrality this equilibrium still holds. Compared to the conditions in Proposition 2, however, the range of values of office supporting the equilibrium is now smaller and the values of $p_{R}$ are higher.

Proposition 6: If $\frac{1}{2}\left(\frac{p_{C}}{p_{C}+p_{L}}-p_{C}\right)<p_{R}<\frac{1}{2}\left(1-p_{C}\right)$ and $\frac{p_{C}}{2}<w<1-p_{L}-\frac{p_{C}}{2}$, there exists a separating Perfect Bayesian Equilibrium where:

- candidates play:

$$
S^{*}=\left(\left(x_{L}^{1}=0, x_{L}^{2}=0\right),\left(x_{C}^{1}=0, x_{C}^{2}=\frac{1}{2}\right),\left(x_{R}^{1}=1, x_{R}^{2}=1\right)\right) ;
$$

- voters' beliefs are :

$$
\mu_{L \mid 0, S^{*}}=\frac{p_{L}}{p_{C}+p_{L}}, \mu_{C \mid 0, S^{*}}=\frac{p_{C}}{p_{C}+p_{L}}, \mu_{C \mid \frac{1}{2}, S^{*}}=\mu_{R \mid 1, S^{*}}=1 ;
$$

- voters choose: $\gamma_{p}(0)=1$ and $\gamma_{p}\left(\frac{1}{2}\right)=\gamma_{p}(1)=0$.

In the most interesting case, the separating equilibrium where both leftist and moderate candidates are reelected, risk neutrality also leads to less restrictive conditions on the value of office and, as a consequence on the shared prior probability of leftist candidates. As stated in Proposition 4.7 the equilibrium holds for higher values of $p_{L}$ and of $w$ when compared to Proposition 4.3.

Proposition 7: If $w<\frac{1}{2}\left(1-p_{C}\right)-p_{L}$, there exists a separating Perfect Bayesian Equilibrium where:

- candidates play:

$$
S^{*}=\left(\left(x_{L}^{1}=0, x_{L}^{2}=0\right),\left(x_{C}^{1}=\frac{1}{2}, x_{C}^{2}=\frac{1}{2}\right),\left(x_{R}^{1}=1, x_{R}^{2}=1\right)\right)
$$


- voters' beliefs are:

$$
\mu_{L \mid 0, S^{*}}=\mu_{C \mid \frac{1}{2}, S^{*}}=\mu_{R \mid 1, S^{*}}=1 ;
$$

- voters choose $\gamma_{p}(0)=\gamma_{p}\left(\frac{1}{2}\right)=1$, and $\gamma_{p}(1)=0$.

Thus two of the equilibria found under risk neutrality - one where all candidates choose the same policy and another where they all pool on the policy preferred by the poor - hold for a higher range of parameter values than the corresponding equilibria found under risk aversion. This difference is clear when we compare Figures 1 and 2. This suggests that, given the assumptions made, risk aversion leads poorer voters to reelect incumbents that are relatively more redistributive than they would were they risk neutral.

Proposition 8: If $w<|1-a|\left(1-p_{C}\right)-p_{L}$, there exists a separating Perfect Bayesian Equilibrium where:

- candidates play:

$$
S^{*}=\left(\left(x_{L}^{1}=0, x_{L}^{2}=0\right),\left(x_{C}^{1}=a, x_{C}^{2}=a\right),\left(x_{R}^{1}=1, x_{R}^{2}=1\right)\right) ;
$$

- voters' beliefs are:

$$
\mu_{L \mid 0, S^{*}}=\mu_{C \mid \frac{1}{2}, S^{*}}=\mu_{R \mid 1, S^{*}}=1 ;
$$

- voters choose $\gamma_{p}(0)=\gamma_{p}(a)=1$, and $\gamma_{p}(1)=0$.

As stated in Proposition 8, the lower the value of office and, as a corollary, the lower the shared probability of a left candidate, the less redistributive an incumbent can be and still get reelected. Compared to the results under the assumption of risk aversion stated in Proposition 4, under risk neutrality candidates might care more about office and left candidates can be perceived as relatively more common and the equilibrium still holds. Thus under this set up, and as noted earlier, risk aversion can work to the advantage of poor voters. 
Figure 1: Equilibrium conditions: Proposition 4.1 (left) and 4.3 (right)

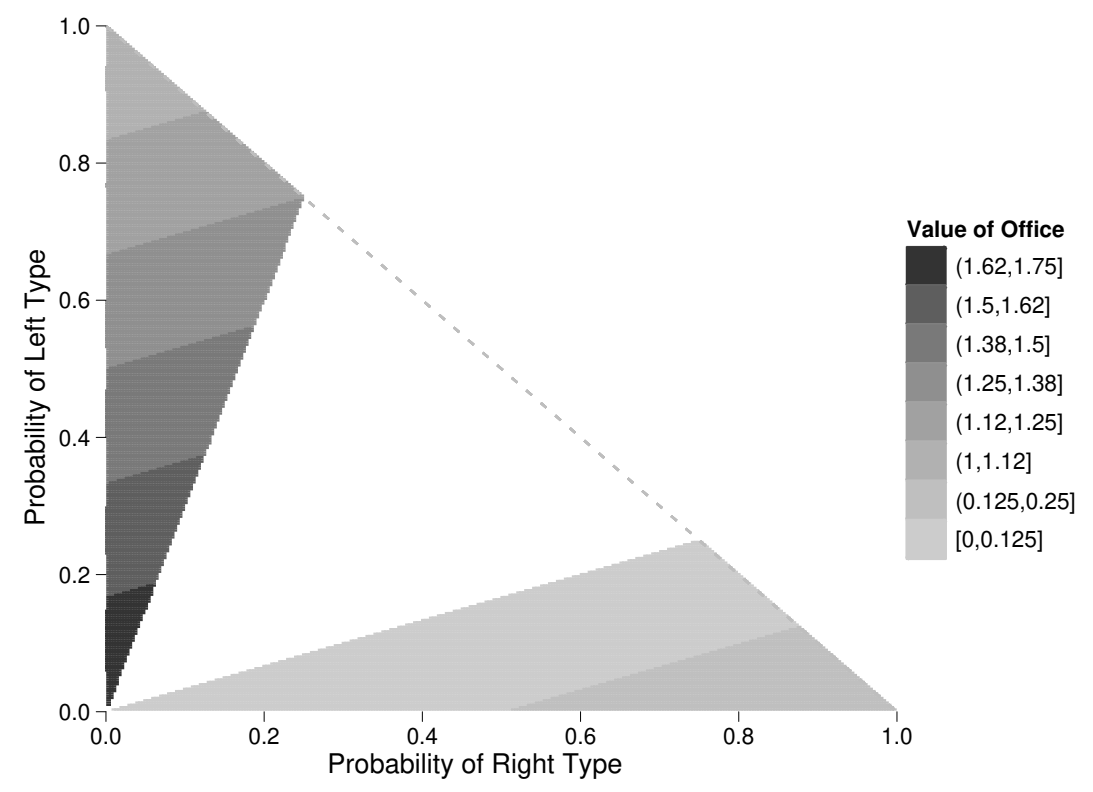

Notes: The values of office displayed correspond to the lower bound in the case of Proposition 4.1 - condition supporting equilibrium is $w>2-p_{L}-\frac{p_{C}}{4}$ - and the upper bound in the case of Proposition 4.3 - condition supporting equilibrium is $w<\frac{1}{4}\left(1-p_{C}\right)-p_{L}$. For illustration purposes I categorized the values of office.

Figure 2: Equilibrium conditions: Proposition 5 and 7

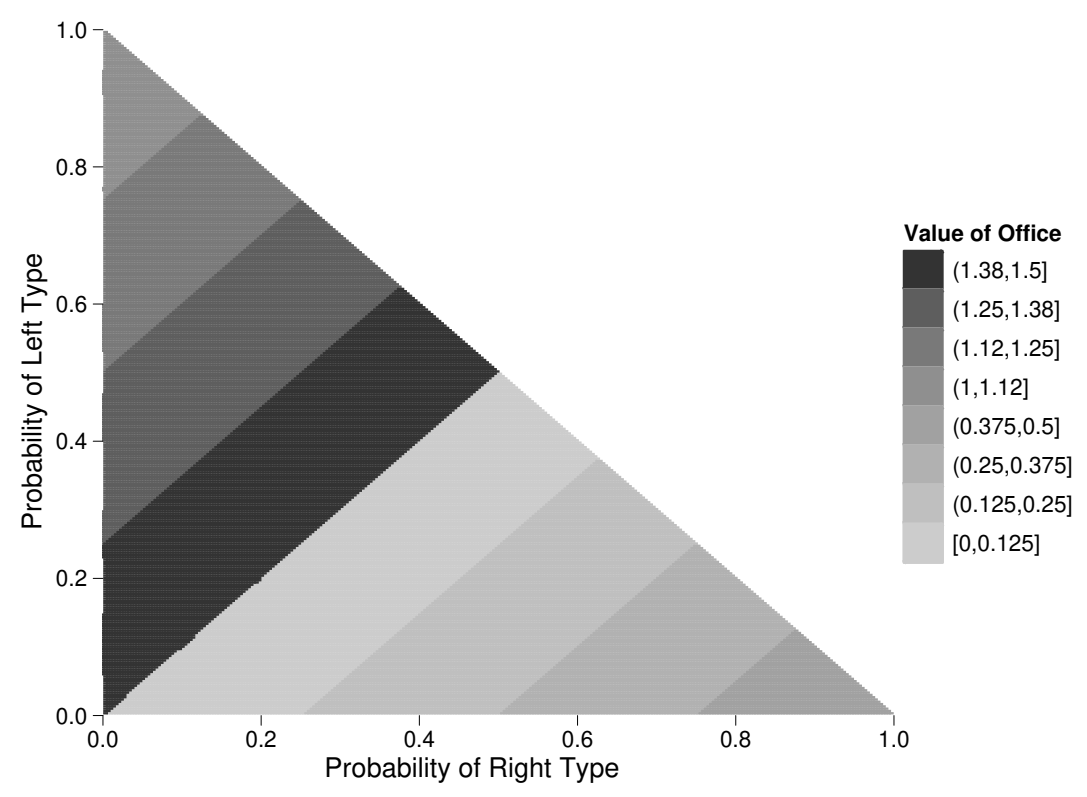

For illustration purposes I categorized the values of office. They are actually continuous, but given the jump from 0.5 to 1 that occurs from one equilibrium to the next, a continuous shading would not be very informative 


\section{Empirical Analysis}

In this section I analyze individual level data to explore some of the observable implications of the model. I focus in particular on three factors. First, the model relies on the assumption that voters face uncertainty about the actual policy position of candidates when making a decision at elections. While this is an intuitive assumption, I present evidence suggesting this is indeed the case.

Second, based on the model results, I look for evidence that the separating equilibrium characterized in the previous section (Proposition 3) holds. To recap, the condition supporting this equilibrium was that candidates be relatively policy oriented, as opposed to only caring about winning the elections. The corollary condition was that voters perceive candidates who defend the interests of the poor to be rare. While no data is available to test the main condition, we are able to explore the plausibility of its corollary.

Finally, if that separating equilibrium holds, incumbents would seek to implement their own ideal policy. This means after observing an incumbent in office, voters should be able to update their beliefs about this representative's actual policy inclinations. Thus uncertainty about the ideological location of an incumbent running for reelection would be lower relative to "unknown challengers".

I address each of these implications in turn. First, I provide evidence of uncertainty looking at different ways of measuring it. I then compare these measures across candidates to check whether voters seem to know more about incumbents than challengers. Finally, I investigate the extent to which individuals perceive pro-poor candidates as rare. In this case I perform two simple exercises. First, I compare individuals' evaluations of candidates' positions with those provided by legislators. Second I explore the relationship between uncertainty and placements, to check whether more uncertainty is associated with placing candidates in particular ideological positions.

The main challenge to studying uncertainty is one of measurement. Asking people directly what they know about the policy inclinations of candidates is the only way to get at the issue. In the analysis that follows I look at individual placements of candidates to the presidency on an ideological scale ranging from pro-poor inclinations to pro-rich ones. The scale defined in terms of 
interests of the poor versus those of the rich and that regarding a very specific redistributive policy, is particularly close to the subject of this study and less susceptible to misinterpretations by survey respondents compared to the commonly used left-right scale.

The data utilized comes from three sources. Data for the 1998 presidential election comes from a survey conducted in September of that year by Vox Populi, a private polling firm ${ }^{5}$. The sample of 3266 respondents was drawn to be representative of the voting age Brazilian population (16 years old or older). Data for 2006 comes from the LAPOP survey conducted that year with a representative sample of citizens 18 years old or older (1214 respondents). Finally, data for the latest presidential elections of 2010 are from the Brazilian Electoral Panel Studies project (BEPS). This rich dataset is composed of three waves of interviews (March, August, and November of 2010), with a core of observations in panel format. The samples were drawn to be representative of the adult population in the country and amounted to 2482, 908, and 1221 respondents in each wave respectively. The items used were worded as follows:

Ideological Placement (1998) I will read to you some qualities candidates possess. Could you tell me, in your opinion, whether each of the following candidates have the will to improve the lot of the poor? (1) Yes, (2) No, (3) Don't know.

Ideological Placement $(\mathbf{2 0 0 6 , 2 0 1 0 )}$ It is said that some politicians defend the interests of the poor, while others defend the interests of the rich. I would like you to give a score from one to ten to each of the following candidates depending on how much they defend the interests of the poor (where 1 means the candidate does not defend the interests of the poor and 10 means they defend the interests of the poor to a great extent (for the purposes of the analysis, the scale was reversed so that 1 would mean pro-poor or "left").

When asked these questions, respondents may refrain from providing an answer, thus conveying uncertainty, or they may, no matter how uncertain they are, still provide one. Two pieces of information can be used for estimating uncertainty. The rate of "don't know" answers and the variance of the distribution of respondents' placement of candidates. This last one deserves a word of caution, however. On the one hand, if there is a high degree of uncertainty regarding

\footnotetext{
${ }^{5}$ The data is available online at the Consórcio de Informações Sociais.
} 
the ideological preferences of a given candidate, individuals' placements of this candidate on the scale could vary considerably across respondents. On the other hand, if all uncertain respondents provide guesses to these placements derived from a common prior belief about challengers' types, this variance could be low $^{6}$.

\subsection{How Much do Voters Know About Candidates Policy Positions?}

The basic assumption in the model developed in the previous chapter is that individuals are uncertain about the actual ideological orientation of candidates during elections. This topic has received considerable attention in the US case. It is not, however, well studied in countries like Brazil, where this kind of uncertainty is presumably much more prevalent, given the number of parties and their relatively short history.

The most crude measure of uncertainty is actual nonresponse rates to ideological placement items. In 1989, the first presidential elections after democratization, when asked by Datafolha about the policies their preferred candidate favored that they thought was important, one third of respondents answered they didn't know. The survey was conducted less than one month before the elections. This figure changed somewhat depending on the respondents' level of education. Among those with primary or less - around $70 \%$ of the sample $-39 \%$ answered "don't know". Among those with college only $16 \%$ did so, and among those with secondary education about one fourth admitted not knowing.

This picture has not changed much over the course of the years. Figure 3 displays the proportion of DK answers to ideological placement items in three subsequent elections for comparison. In 1998 - the third presidential election, where Fernando Henrique Cardoso (FHC) was the incumbent running for reelection - when asked whether each of three contenders - FHC, Lula and Ciro - had will to improve the lot of the poor, answers varied. When the question referred to the incumbent, FHC, only $13 \%$ answered "don't know" (represented in Figure 3 by a gray triangle in the column corresponding to the 1998 elections) and about half said "yes". With regards to Ciro Gomes,

\footnotetext{
${ }^{6}$ To illustrate with the case at hand, if all respondents who do not know much about a candidate place that candidate towards the right (as expected based on the model and its results of a shared prior that rightist types are much more common), then we would not expect too great variance in the answers.
} 
answers were very close to a random draw: one-third answered "don't know", another third said "yes" and the remaining third "no". Evaluations of Lula lied in between with $46 \%$ of respondents answering "yes" and 17\% "don't know" 7 .

Figure 3: Nonresponse rates to candidate ideological placement question

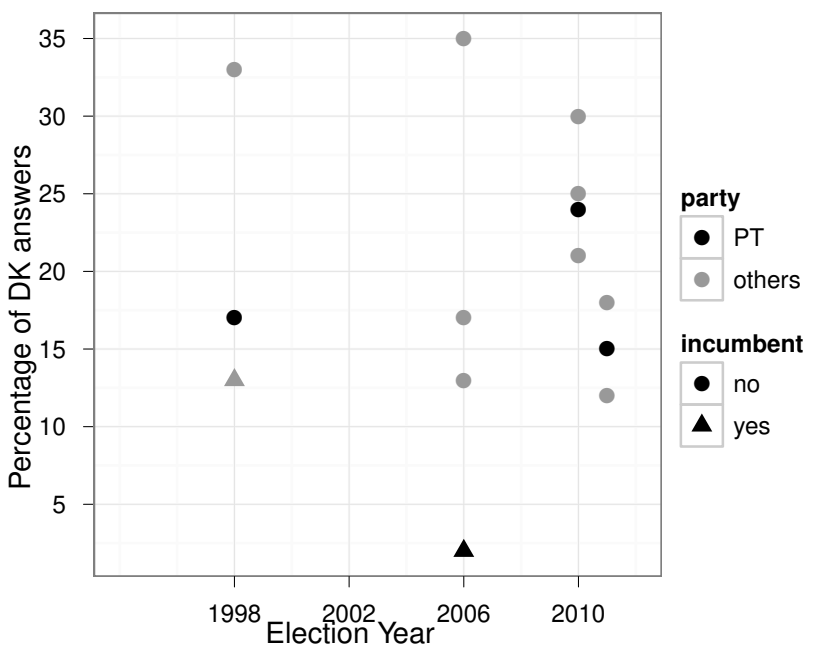

Each marker corresponds to one of the main candidates in the presidential election that year. They represent the percentage of respondents unable to provide an estimate of that candidate's ideological placement on a pro-poor/pro-rich scale. Markers are distinguished based on the candidate's party (whether affiliated to the Worker's Party or not) and whether she was an incumbent running for reelection or not. No data is available for the 2002 elections. Source: 1998 Vox Populi, 2006 LAPOP, 2010 BEPS

Nonresponse rates in 2006 and in two waves in 2010 (the first and the last wave) fall roughly around the same range. In 2010, where we have two waves for comparison, we notice some tendency for the rates to drop as electoral campaigns progress.

An alternative way to simply looking at the raw incidence of nonresponse (where we miss those respondents who provided an answer even though uncertain about it) is to compute predicted probabilities of nonresponse for each respondent and then use them to estimate the candidate's rate (Bartels, 1986). Two assumptions are made in this case. First, it is assumed that all individuals share the same "uncertainty" threshold, that is, they only provide an answer to placement questions if they fall below that threshold. Second, it is assumed that individual characteristics can account

\footnotetext{
${ }^{7}$ Relative to the 1989 survey results, differences in educational attainment were not very pronounced in terms of incidence of "don't knows" by candidate. Considering only those respondents with primary education or less, the rates of "don't know" were $36 \%$ for Ciro, $22 \%$ for Lula and $16 \%$ for FHC.
} 
for the incidence of non-response and can thus be used to predict individual probabilities of being uncertain about a candidate and a policy. Replicating the analysis in Bartels (1986) using the LAPOP and the BEPS, however, suggests that one or both assumptions seem too strong in the case of Brazil.

While the signs and significance of individual level characteristics are plausible ${ }^{8}$, they only account for $1 \%$ of the variation in non-response (compared to $25 \%$ in the US following a similar specification).

\subsection{What do voters know about candidates?}

Following the results in the previous section, the equilibrium that accounts for low rates of redistribution is characterized by two features. One is that politicians tend to implement their preferred policy if elected. Thus their choices while in office can convey to voters information about their personal ideological inclinations. As a result we would expect voters to have less uncertainty about the preferences of incumbents than about the preferences of challengers.

The other feature is that voters share a common belief that the most prevalent type of politician is a rightist type. Thus when in doubt about the ideological inclination of an electoral contender, voters who venture a guess would likely place that candidate towards the right of the spectrum. In this subsection I look for evidence of both features.

On the first issue, I begin the discussion going back to Figure 3. The non-response rate corresponding to incumbents running for reelection is depicted by a triangle (FHC in 1998 and Lula in 2006). I also singled out the candidate for the Worker's Party (PT), which was Lula in 1998 and 2006 and Dilma in 2010. Notice that in the 2010 elections there was no incumbent in the race and that Ciro Gomes, featuring as one of the potential candidates in the first wave, decided not to enter the race. Two patterns stand out in the picture.

First, incumbents have the lowest rate of nonresponse (FHC in 1998 and particularly Lula in

\footnotetext{
${ }^{8}$ The covariates are: level of education, exposure to the media, interest in politics, race, gender, extreme ideological stance, and level of information about politics (captured by three items on presidential term limit, name of US president, and number of states in Brazil). Out of this list three were consistently significant: the higher the level of education the lower the probability of non-response, the same for higher interest in politics, and finally, females tend to be more likely not to respond than males.
} 
2006). If we compare the rates of "don't know" for Lula, who was a challenger in all elections from 1989 to 2002 and the incumbent in 2006, we notice a sharp decline suggesting respondents were better able to provide an estimate of his policy stance after observing him serve one term in office.

The second pattern is that the knowledge voters have from an incumbent does not seem to carry over to a challenger running under the same party in future elections. The reason I singled out PT candidates in the figure is that according to experts and ideal point estimates in the literature, this is the most cohesive party in Brazil. Even though Lula campaigned relentlessly for Dilma, respondents to the BEPS survey did not feel any more certain about her policy positions than they did about the other candidates in the race.

An additional way of evaluating uncertainty is to compare the individual ratings to more informed estimates of candidates' or their parties' placement. Given the data limitations, such comparisons are, again, very exploratory, but insightful nonetheless. They can, in fact, shed light on both uncertainty and the extent to which respondents believe some types to be more common than others.

First, where the individual assessments diverge from other accepted estimations of the positions of candidates, there is, at least to some extent, sign of uncertainty ${ }^{9}$. That is, respondents might just be taking their best guess at placing candidates on the scale. Second, if this is the case, then the natural question is how likely are these guesses the result of a particular belief about the distribution of candidates as opposed to a simple random estimate? In other words, are the answers, or "guesses" we observe likely to come from a prior belief that candidates sharing the preferences of the poor are rare relative to moderate and rightist types?

As pointed out earlier, if the separating equilibrium found in the previous section provides a good characterization of the situation in unequal new democracies, individuals should be able to update their beliefs about the actual ideological inclination of the incumbent, because incumbents always

\footnotetext{
${ }^{9}$ Ideally this should be evaluated based on individuals self-placement or some other reference point so that ratings from different individuals are in fact comparable. Roughly speaking, however, the higher the disagreement between more informed estimates of candidates placement and individuals' placement the more likely it is that uncertainty played a role. The other reason can be that individuals make mistakes, that they don't know how to infer candidates' policy positions based on what they observe. If mistakes by the individual were the main reason, however, we would probably not find a higher congruence of assessments with respect to incumbents. Individuals would likely be wrong about them too, but that is not what the data suggests.
} 
try to implement their own ideal policies. Thus if we find evidence that there is less uncertainty regarding the incumbent, we find evidence in favor of the separating equilibrium and against the other two pure strategy equilibria found.

Figure 4: Placement of candidates and parties on ideological scale (1997-1998)

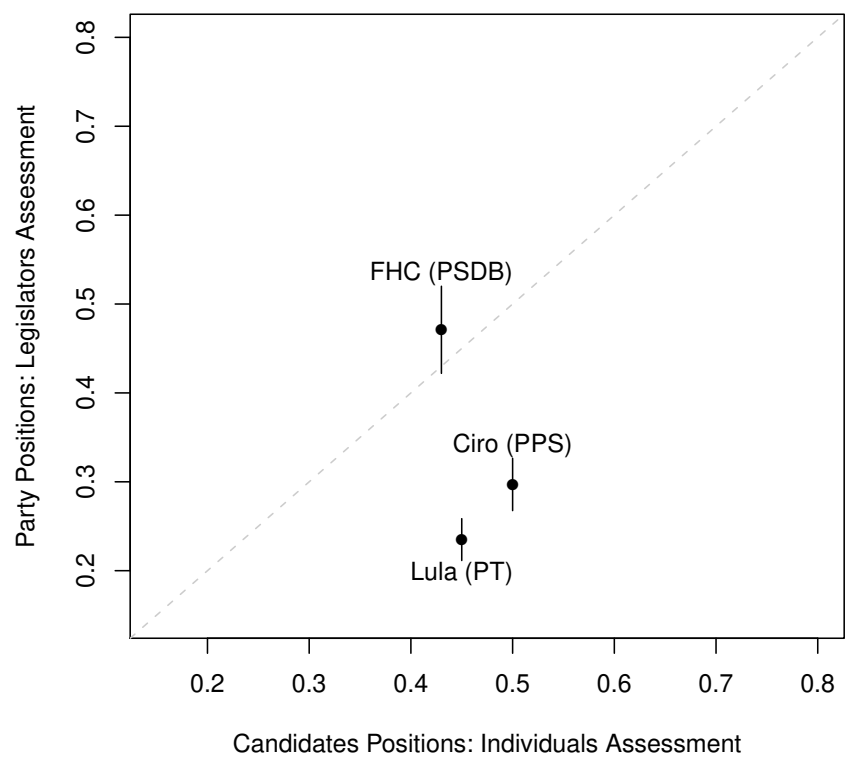

Source: Data on legislators' assessment of party positions were taken from Power and Zucco Jr (2009). Vertical bars represent the $95 \%$ confidence intervals around the estimates. Candidates positions correspond to the proportion of respondents to the Vox Populi survey in 1998 saying that the candidate was pro-rich.

Beginning with 1998, where FHC was the incumbent running for reelection, about $50 \%$ of respondents answered that $\mathrm{FHC}$ was committed to the cause of the poor. This number was slightly lower for Lula (46\%) and even less for Ciro (34\%). Those with primary education or less were slightly less likely to see Lula as pro-poor (42\%) than the average and less likely to see him as pro-poor compared to FHC (53\% thought FHC had the resolve to improve the situation of the poor).

Lula, however, is considerably more to the left than FHC. Estimates of the ideological positions of parties based on legislators' assessment place the PSDB (FHC's party) around the center and both the PT (Lula's party) and the PPS (Ciro's party) towards the left of the ideological spectrum in 1997(Power and Zucco Jr, 2009). These estimates are plotted in Figure 4 together with the 
proportion of respondents in 1998 who rated each of the candidates as being pro-rich ${ }^{10}$.

The individual ratings of FHC are relatively close to those obtained from legislators (closer to the 45 degree line in the graph). The evaluations of both Lula and Ciro, however, seem considerably off-mark relative to the legislators' party ratings. The fact that both Ciro and Lula were ranked by respondents as more rightist than they actually were, suggests the conditions supporting the separating equilibrium might in fact hold. That is, when asked to assess the policy position of an "unknown challenger", voters believing left types are rare would tend to place that candidate towards the right.

The view of FHC as more leftist than Lula is also in line with voting results. In 1998 the poor were more likely to vote for FHC than for Lula. The reason might be exactly the one proposed in the separating equilibrium. Although poor voters saw him as a moderate, they reelected him because they expected the challengers to be further to the right.

Thus based on the 1998 data, figures suggest that there was more uncertainty about the placement of the challengers than that of the incumbent. Moreover, the challengers tended to receive ratings placing them further to the right of the policy spectrum. If respondents believed that left types were more common, we would expect the opposite to hold. That is, challengers being more likely to be placed towards the left of the scale. In addition, the fact that FHC was seen as a moderate, lends plausibility to the results obtained from the separating equilibrium. In particular the part saying that moderates would be reelected even if poor voters were fully aware of her or his position.

Moving now to 2006, based on the LAPOP data, respondents were more likely to rate the challengers - Gerald Alckmin, Heloísa Helena, and Cristovam Buarque - as either moderate or pro-rich. Lula, the incumbent, was placed rightly towards the left. More respondents were likely to rank him as "pro-poor" in 2006 than in 1998, when he was a challenger.

In fact, for the placement of Lula in 2006 to be similar to those in 1998 we would have to assume that anyone placing him around the third position or higher on the ideological scale from 1 (pro-poor) to 10 (pro-rich), believed he was not committed to the cause of the poor. Considering

\footnotetext{
${ }^{10}$ These proportions were calculated coding the "don't knows" as missing. If instead we use the whole sample, the discrepancies between Lula's and Ciro's rating relative to their parties' placement is even starker.
} 
only those respondents with primary education or less, we would need to assume anyone placing Lula somewhat after the second position or higher believed he had no will to improve the lot of the poor. Another way to see that is by simply splitting the 2006 scale in two. Then $64 \%$ of respondents rated Lula as pro-poor in 2006 compared to $46 \%$ in 1998. This figure goes to $69 \%$ among the least educated in 2006 compared to $42 \%$ in 1998.

In 2010 a similar pattern occurs. Based on the first wave of interviews, Dilma (Lula's candidate) was placed towards the left of the spectrum, while the remaining contenders were placed towards the right. Marina, a former minister in the government of Lula and former member of the PT was placed towards the right of Serra a more moderate candidate.

In order to test the hypothesis that respondents' placement answers were coming from a prior belief that candidates are more likely to be rightist, I run a simple Bayesian analysis. First I rescale the answers to the 0 to 1 interval. Assuming the ratings have a beta distribution I estimate the scale and shape parameters in each case - one set of parameters per candidate. I can then compare differences in the estimated distributions likely to have yielded the answers we obtained from the survey for each candidate. The model is given in the appendix. I follow the parameterization in Branscum et al. (2007).

Figure 5 displays the posterior density of the estimated mean of the beta distribution likely to have yielded the responses in the LAPOP survey by candidate. Notice that the estimated mean in the case of Lula is significantly to the left of his main contenders. The challengers tend to be clustered towards the right side of the spectrum as pointed out earlier. An interesting question that arises is how closely these placements based on individual assessments are to other estimates of candidates position?

Heloísa Helena belongs to the PSOL, an extreme left faction of the PT that decided to split in response to the party's moderation in the past couple of years. Thus the fact that Heloísa Helena is considerably to the right of Lula is quite interesting. It is highly suggestive of the tendency of voters to believe callengers are not likely to be pro-poor.

Cristovam Buarque ran as the candidate for the PDT, another left party. His campaign in 2006 was heavily based on increasing the quality of public provision of education. He was the head of the 
Figure 5: Posterior distribution of estimated mean ideological placement

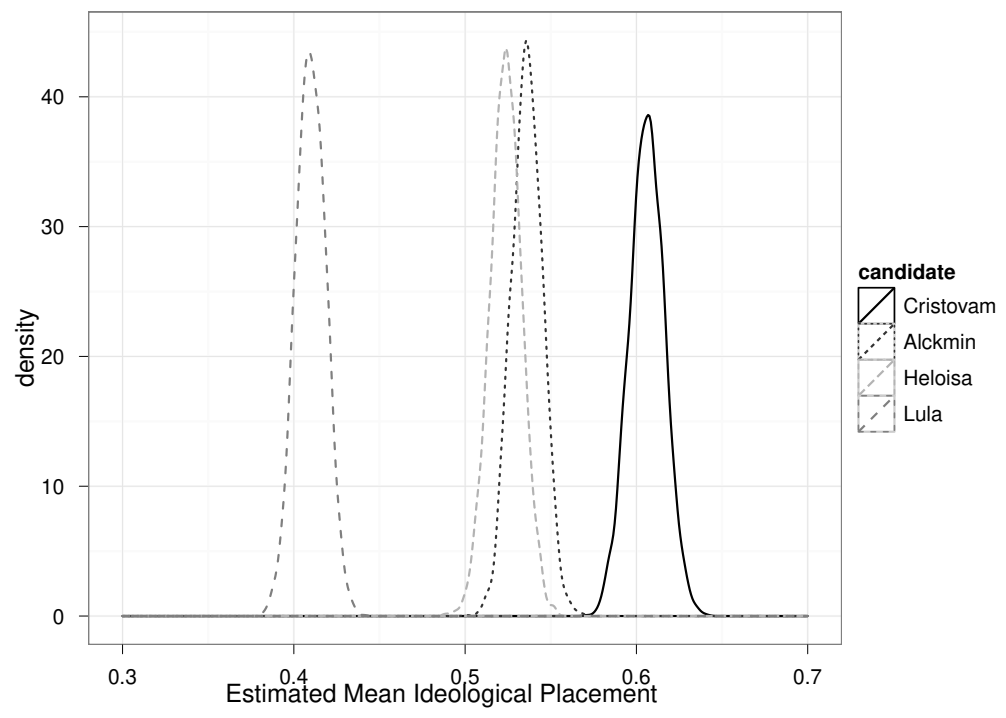

Lines represent the posterior distribution of the estimated mean of the Beta Distribution likely to have yielded the raw placement answers obtained from respondents. Source: Author's calculations based on the LAPOP data

think thank that designed the Bolsa Escola program, a conditional-cash-transfer program requiring recipients to attend school on a regular basis. He was the first to implement the program in the Federal District during his term as a governor (1995 - 1998) for the PT. During Lula's first term in the presidency, Bolsa Escola was incorporated into Bolsa Famlia, a more encompassing transfer program that now benefits millions of poor families in the country. In sum, a member of a left party and co-creator of the most popular conditional-cash-transfer program in the country was rated as the most rightist candidate by respondents. This suggests individuals ideological assessments of Cristovam are very likely the result of a prior belief that "unknown challengers" are more likely to be rightists.

Geraldo Alckmin, in turn, ran under the PSDB, the party of the former president FHC. Respondents placed him somewhat towards the right, which seems compatible with the position of his party. Unfortunately it is impossible to assess how much of this consistency is due to lucky guesses as opposed to informed responses.

Finally Lula was the candidate for the Workers Party (PT) a relatively cohesive left party. In 
order to discuss his placement it is worth considering both the time trends and his position relative to his main contenders (both from the PSDB) in 1998 and 2006. Based on legislators' assessment ${ }^{11}$ of party positions, Power and Zucco Jr find that during the period 1990 to 1993 the PT and the PSDB tended to converge to positions at the left of the median legislator. From 1993 to 2001, however, they begin to diverge with both the PT moving to the left and the PSDB moving to the right past the median legislator.

Going back to the individual assessments of candidates, the year where respondents rated FHC as more "pro-poor" than Lula - 1998 - was the year where their parties diverged the most on ideological leanings. Lula's ratings were then considerably more to the right than that of his party. This suggests a right bias in his evaluations at a year where respondents had not yet had the opportunity to observe him in action.

When we move to 2006, where some ideological convergence between the PT and the PSDB takes place, Lula receives mostly pro-poor ratings, even more than he had in 1998. Thus taking these party positions into account, the shift in perception regarding Lula was considerable. Were his rating in 1998 to reflect his party position then, they should have been even more to the left than those in 2006.

Moving on to 2010, we observe similar patterns (Figure 6). Dilma, under the higher uncertainty pre-campaign period - corresponding to the first wave of the survey - is placed to the right of where she ends up towards the end of the elections (once voters had the opportunity to learn about her closeness to Lula). Also Marina, a leftist candidate, begins the year seen as mostly rightist. There are thus signs that some learning takes place during the campaign.

A fair question at this point is whether poorer respondents differ in their evaluation of candidates' placement from richer ones. The idea is that voters could just be placing unknown contenders either closer or further away from their own positions, as is assumed by some authors. Splitting the sample into two income groups - one below the median income and the other above the median

\footnotetext{
${ }^{11}$ While the scale presented to legislators was the same that was presented to respondents in the LAPOP survey (1 - 10), the wordings were different. Legislators were asked about left (1) and right (10) ideological placement, while respondents were asked about pro-poor (10) and pro-rich (1). This last scale was reversed for the analysis. These differences make precise comparisons difficult. Moreover, the methodology employed by Power and Zucco Jr differs from the one employed here, since they have data on legislators self-placement on the same scale available for computations. For details on the methodology the reader is referred to the authors' paper.
} 
Figure 6: Estimated placement before campaign and between election rounds, respectively
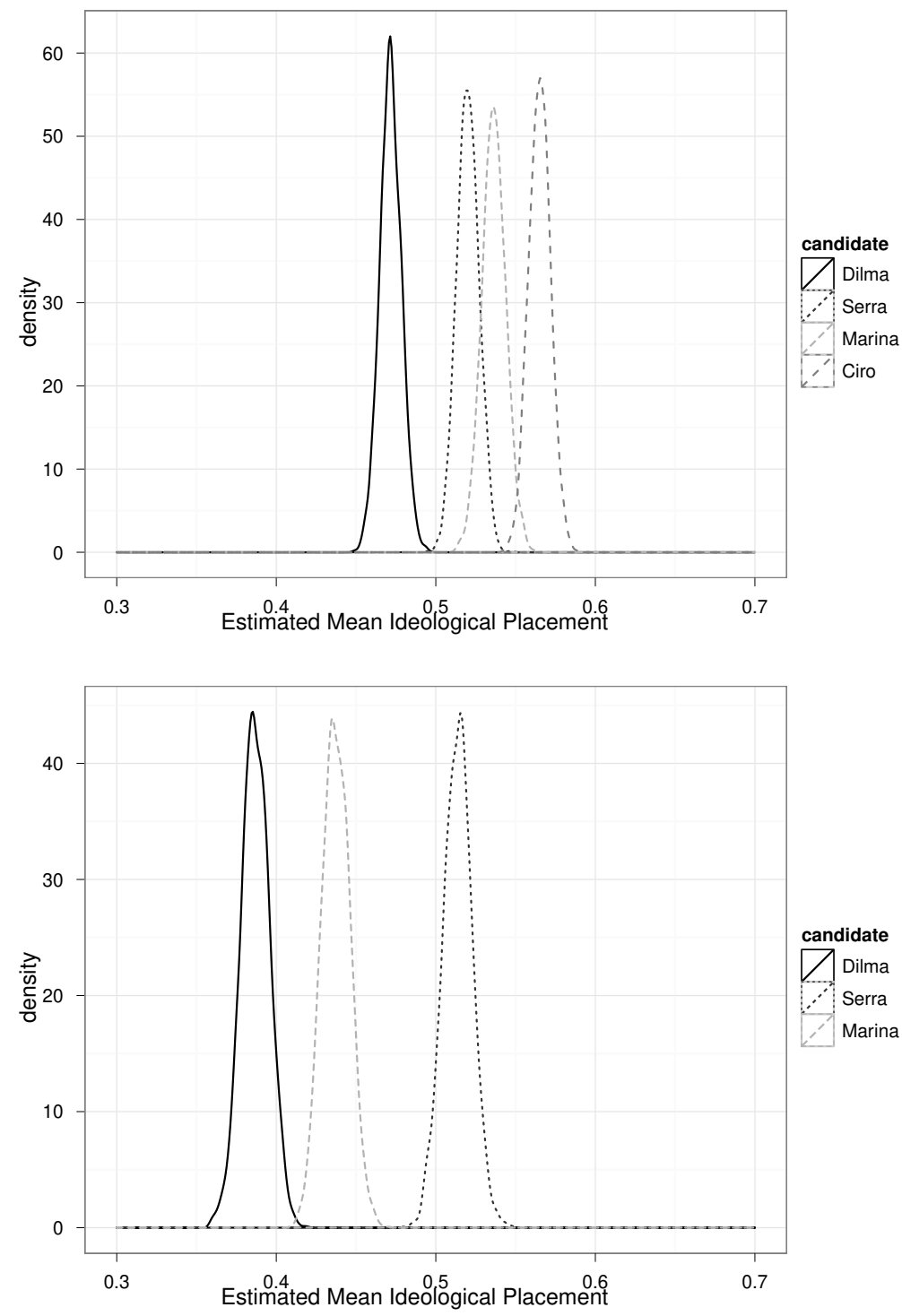

Lines represent the posterior distribution of the estimated mean of the Beta Distribution likely to have yielded the raw placement answers obtained from respondents. Source: Author's calculations based on the BEPS data.

income - shows that the placements are very similar (Figure 3.2) suggesting it is not conditional on a respondent's socio-economic position.

Taking the analysis a step further, I look at the relationship between levels of uncertainty and placement. Contrary to what is commonly assumed - that under uncertainty, respondents place 
Figure 7: Placement among poorer and richer respondents, respectively
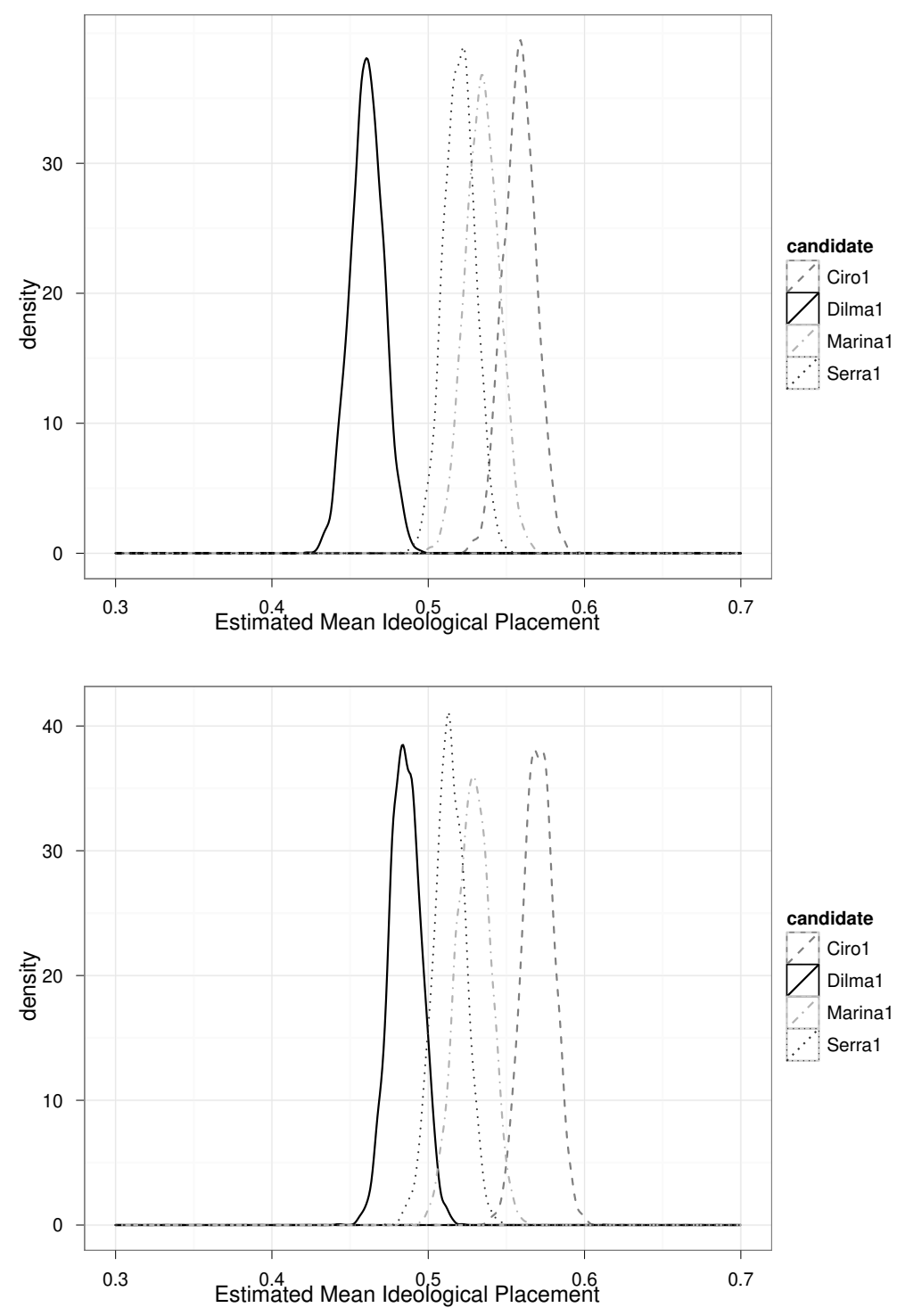

Lines represent the posterior distribution of the estimated mean of the Beta Distribution likely to have yielded the raw placement answers obtained from respondents. Source: Author's calculations based on the BEPS data. 
Figure 8: Relationship between average placement and nonresponse rates

The mean corresponds to the average location of each candidate on the pro-poor/pro-rich scale. DK corresponds to the proportion of nonresponse to that question by candidate. Source: LAPOP and BEPS.

candidates in the middle of the scale - the data seem to sugest that voters place candidates more to the right. In this first set of results I look at some aggregate measures of uncertainty and placement by candidate. I have in total 14 observations pooling 2006 and 2010. I find a significant association between incidence of DK answers and placement leaning towards the right in all three instances analysed.

First I look at a very crude measure of placement as the average of all individual ratings and two measures of uncertainty: nonresponse rates and the variance of given answers to the placement question. I find a significant relationship between the incidence of DK answers and the average placement (Figure 8), but no statistically significant relationship between average placement and the variance of placements.

Second, using the estimation based on the Beta distribution, I find the same pattern of results. Significant relationship between nonresponse rate and the estimated mean placement (Figure 9), but no significant correlation between the estimated variance (based on the Beta model) and the estimated average placement.

Third, I split the sample into two income groups, for the same reasons mentioned earlier. To check whether the relationship found holds irrespective of the socio-economic position of the respondent. Again, the same results hold.

The lack of significance with measures of variance could be suggesting two issues. First that, as noted earlier, the assumption of voters sharing a common prior is valid. In that case, variances are not significantly increased under uncertainty because the shared prior belief restricts the set of possible answers respondents provide. Second, it might suggest that we consider imputing data for DKs. The reasoning is that variance is calculated based on those who actually ventured an answer, or in the words of Bartels, those who crossed the threshold of uncertainty. Thus the variance of the final distribution - which excludes those most uncertain - might be biased downwards. In order 
Figure 9: Relationship between estimated average placement and nonresponse rates

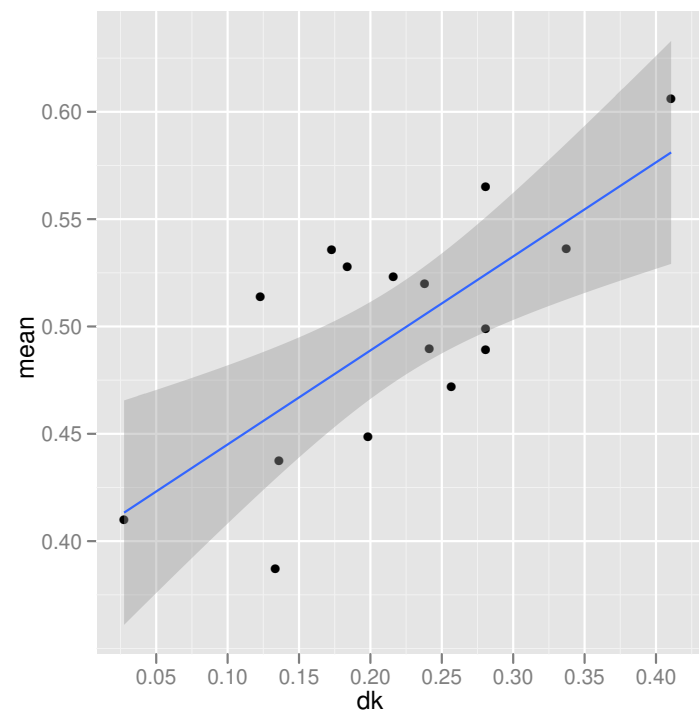

The mean corresponds to the average location of each candidate on the pro-poor/pro-rich scale. DK corresponds to the proportion of nonresponse to that question by candidate. Source: LAPOP and BEPS.

Figure 10: Relationship between estimated average placement and nonresponse by income (poor and rich respectively)
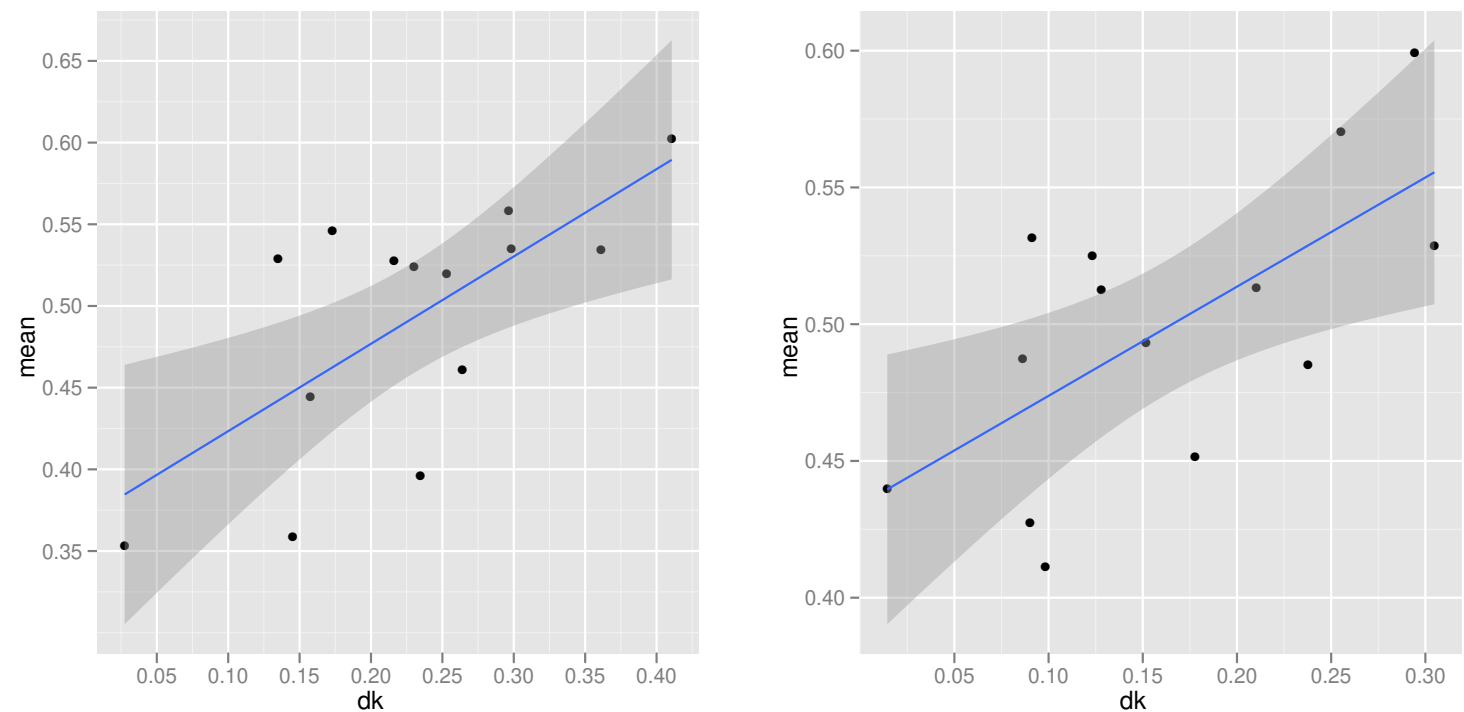

mean corresponds to the average location of each candidate on the pro-poor/pro-rich scale. DK corresponds to the proportion of nonresponse to that question by candidate. The cut-off point to generate the two groups was the median income in the sample. Source: LAPOP and BEPS. 
to check that possibility, I imputed DK answers with placements drawn randomly from a uniform distribution, so that locations would remain the same, while the variances would supposedly increase the higher the incidence of DKs. Even using this procedure, measures of variance continue to show no significant relationship with placement.

To summarize, the data suggests that voters face uncertainty about the policy positions of candidates during elections. This uncertainty is visible both in terms of incidence of respondents admitting they do not know about the ideological inclinations of candidates, and also among those who provided answers. Compared to ideological placements based on legislators assessments, respondents' ratings in the 1998 and 2006 surveys analyzed not only differed to a greater extent when

it came to rating challengers as opposed to incumbents, but also suggested that answers could have resulted from a prior belief that left leaning candidates tend to be rare.

Regarding the ratings of incumbents - FHC in 1998 and Lula in 2006 - individuals' assessments seemed more consistent with legislators rankings of their parties, thus suggesting that some learning about the policy positions of incumbents does indeed take place.

\section{Conclusion}

Despite long held expectations that the extension of the suffrage in unequal societies would lead to high redistribution, many new democracies remain remarkably unequal. In this paper I address this puzzle with a focus on the electoral process. I develop a model of elections as a game of incomplete information to explore how uncertainty (pervasive in new democracies), candidates' motivation (policy vs. office), and beliefs about their ideological inclinations affect what policy interests are likely to be represented in the political process.

Three important insights arise from the model. First, regarding the role of candidates' motivations, low redistribution in unequal democracies can be a sign that candidates are relatively policy, as opposed to office, oriented. Policy orientation leads candidates to choose their own ideal policies once in office. That is, both moderates and right types would not try to "mimic" a left type in order to garner votes. If candidates were purely office seekers, they would have an incentive to implement the policy favored by a majority to win the election. If that were the case, however, we 
would likely observe more rather than less redistribution.

The second point refers to the importance of voters perceptions of the ideological locations of candidates. The particular equilibrium addressing the central question of this study suggests that voters believe candidates sharing the preferences of the poor majority to be relatively rare. This can lead poor voters to reelect center or center-right incumbents, even if they are aware of these preferences. This is because they expect a random challenger to be relatively more to the right. Hence the feeling of distance from and disillusionment with most politicians - common in many new democracies - can serve to perpetuate outcomes that are disadvantageous for the majority.

Finally, the model provides an account of voters' behavior that does not rely on suppositions of irrationality, ignorance, and disregard for policy. Even under the assumption that they are as capable as any other voter to evaluate policy and update beliefs about incumbents' policy positions, it can be optimal for them to reelect incumbents who favor less redistribution than they do.

I analyzed individual level data gathered close to presidential elections in Brazil to evaluate the theoretical model's results. I found that individuals responses to candidates' ideological placements on a pro-poor to pro-rich scale in 1998, 2006 and 2010 indicates they do indeed face uncertainty. Moreover, in line with the theoretical model, this uncertainty seemed higher with respect to first time challengers than incumbents. There were thus clear signs that voters update their beliefs about the policy positions of incumbents. The individual assessments of incumbents ideological placement tended to lie closer than the individual assessments of challengers to the ideological placements of candidates' parties according to the opinion of legislators.

Furthermore, comparisons between legislators' evaluations of challengers' parties positions and the individual assessments of challengers revealed a bias towards the right in individuals' evaluations. That is, respondents' placements of challengers on a policy scale seem to have resulted from the belief that left types are rare. I also found a positive and significant association between measures of uncertainty by candidate and the candidate being placed towards the right, rather than the center, of the ideological spectrum. 


\section{References}

Bartels, L. M. (1986). Issue voting under uncertainty: An empirical test. American Journal of Political Science, 30(4):709-728.

Branscum, A. J., Johnson, W. O., and Thurmond, M. C. (2007). Bayesian beta regression: Applications to household expenditure data and genetic distance between foot-and-mouth disease viruses. Australian and New Zealand Journal of Statistics, 49(3):287-301.

Calvert, R. L. (1985). Robustness of the multidimensional voting model: Candidate motivations, uncertainty, and convergence. American Journal of Political Science, 29(1):69-95.

Constant, B. (1988). Political Writings, chapter Principles of Politics Applicable to all Representative Governments. Cambridge University Press.

Duggan, J. (2000). Repeated elections with asymmetric information. Economics and Politics, 12(2):109-135.

Duggan, J. and Fey, M. (2005). Electoral competition with policy-motivated candidates. Games and Economic Behavior, 51(2):490-522.

Eckel, C., Johnson, C., and Montmarquette, C. (2004). Saving decisions of the working poor: Short-and lont-term horizons. CIRANO: Centre interuniversitaire de recherche en analyse des organisations: $2004 \mathrm{~s}-45$.

Engle-Warnick, J., Escobal, J., and Laszlo, S. (2006). The effect of an additional alternative on measured risk preferences in a laboratory experiment in peru. Centre interuniversitaire de recherche en analyse des organisations: 2006s-06.

Marx, K. (1973). Surveys from Exile: Political Writings. London: Allen Lane.

Meltzer, A. H. and Richard, S. F. (1981). A rational theory of the size of government. Journal of Political Economy, 89:914-27. 
Osborne, M. J. and Slivinski, A. (1996). A model of political competition with citizen-candidates. Quarterly Journal of Economics, 111:65-96.

Powell, G. B. (2000). Elections as Instruments of Democracy. Yale University Press.

Power, T. and Zucco Jr, C. (2009). Estimating Ideology of Brazilian Legislative Parties, 1990-2005: A Research Communication. Latin American Research Review, 44(1):218-246.

Robinson, J. A. (2009). The political economy of redistributive policies. Research for Public Policy, Inclusive Development ID-09-2009,, RBLAC-UNDP. 


\section{Appendix}

\subsection{Proof of Propositions 1 to 3}

Starting by backwards inductions, at her second and last term a candidate maximizes her utility by implementing her ideal policy. This is because no reelection is allowed at this point, thus office motivations do not play a role.

I need to show that in the first period, given the equilibrium strategies and conditions no player has an incentive to deviate. First I consider voters' responses to each possible policy. Then I establish the conditions that make it not profitable for candidates to unilaterally deviate from their equilibrium strategies given voters responses to them. Since the poor form a majority, as long as they are not indifferent between candidates their vote is decisive. Indifference only happens for one specific value of the prior distribution of candidates types out of a continuum of possible values. Therefore I focus on cases where the poor are decisive.

\section{Proof of Proposition 1:}

After observing $x^{1}=0$ given that all types of incumbents choose 0 in equilibrium, no updating occurs. This yields

$$
\begin{aligned}
& E U_{p}(I)=E U_{p}(C h), \text { and } \\
& \gamma_{i}(0)=\frac{1}{2} \text { for all } i .
\end{aligned}
$$

After observing off-the-equilibrium-path policies, voters cannot update their beliefs via Bayes' Rule. In such cases, I apply the divinity refinement (D1) to set these beliefs. Following D1, the deviation is believed to come from the type for whom it would be profitable for the most inclusive range of reelection probabilities. Starting with $C$ the range of reelection probabilities that would make a deviation to $x$ profitable is given by: 


$$
\begin{aligned}
E U_{C}\left(s_{C}^{\prime},\left(s_{L}^{*}, s_{R}^{*}\right)\right) & >E U_{C}\left(S^{*}\right) \\
-x^{2}+w+\gamma^{C} w+\left(1-\gamma^{C}\right)\left(-\frac{p_{C}}{4}-\frac{p_{R}}{4}\right) & >-\frac{1}{4}+w+\frac{1}{2} w+\frac{1}{2}\left(-\frac{p_{C}}{4}-\frac{p_{R}}{4}\right) \\
\gamma^{C} & >\underbrace{\frac{x^{2}-x}{w+\frac{p_{c}}{4}+\frac{p_{R}}{4}}+\frac{1}{2}}_{a(x)}
\end{aligned}
$$

Replicating the same calculations to the other two types yields:

$$
\begin{aligned}
E U_{R}\left(s_{R}^{\prime},\left(s_{L}^{*}, s_{C}^{*}\right)\right) & >E U_{R}\left(S^{*}\right) \\
\gamma^{R} & >\underbrace{\frac{x^{2}-2 x}{w+\frac{p_{c}}{4}+p_{L}}+\frac{1}{2}}_{b(x)}
\end{aligned}
$$

and

$$
\begin{aligned}
E U_{L}\left(s_{L}^{\prime},\left(s_{R}^{*}, s_{C}^{*}\right)\right) & >E U_{L}\left(S^{*}\right) \\
\gamma^{L} & >\underbrace{\frac{x^{2}}{w+\frac{p_{c}}{4}+p_{R}}+\frac{1}{2}}_{c(x)}
\end{aligned}
$$

Comparing these values I get that for all $x, b(x)<a(x)$ and $(x) b<c(x)$. This means deviations are believed to come from the $R$ type. That is, $\mu_{R \mid\left\{\frac{1}{2}, 1\right\}, S^{*}}=1$, leading to

$$
E U_{p}(I)=-1
$$

This is the lowest utility possible for poor voters, thus leading to

$$
\gamma_{p}\left(\frac{1}{2}\right)=\gamma_{p}(1)=0
$$


Now we need to consider profitable deviations on the part of candidates. Given the conditions stipulated so far, any deviation by $L$ means loss of utility, since $L$ would not be reelected for sure and would be further away from $\tilde{x}_{L}$. Thus $L$ will not deviate. Both $C$ and $R$, however, may deviate.

Consider $R$ first. Given voters beliefs any deviation by $R$ results in no-reelection. Of all possible deviations the one bringing highest utility to $R$ is $x^{1}=1$ since utility from office is constant and $x^{1}=1$ maximizes her utility from policy. $R$ 's expected utility from this unilateral deviation, denote it by $s_{R}^{\prime}$, is

$$
E U_{R}\left(s_{R}^{\prime},\left(s_{L}^{*}, s_{C}^{*}\right)\right)=w-\frac{p_{C}}{4}-p_{L}
$$

while

$$
E U_{R}\left(S^{*}\right)=\frac{3}{2} w-1-\frac{p_{C}}{8}-\frac{p_{L}}{2}
$$

The necessary and sufficient conditions for $R$ not to deviate are given by $E U_{R}\left(S^{*}\right)>E U_{R}\left(s_{R}^{\prime},\left(s_{L}^{*}, s_{C}^{*}\right)\right)$. This yields

$$
w>2-p_{L}-\frac{p_{C}}{4}
$$

Now consider $C$. By the same logic above, the most profitable deviation by $C$ is to $x^{1}=\frac{1}{2}$. $C^{\prime}$ 's expected utility from this unilateral deviation, denote it by $s_{C}^{\prime}$, is

$$
E U_{C}\left(s_{C}^{\prime},\left(s_{L}^{*}, s_{R}^{*}\right)\right)=w-\frac{p_{L}}{4}-\frac{p_{R}}{4},
$$

while

$$
E U_{C}\left(S^{*}\right)=\frac{3}{2} w-\frac{1}{4}-\frac{p_{L}}{8}-\frac{p_{R}}{8}
$$

The necessary and sufficient conditions for $C$ not to deviate are given by $E U_{C}\left(S^{*}\right)>E U_{C}\left(s_{C}^{\prime},\left(s_{L}^{*}, s_{R}^{*}\right)\right)$. This yields $w>\frac{1}{2}-\frac{p_{L}}{4}-\frac{p_{R}}{4}$ which is satisfied by (1).

Proof of Proposition 2: After observing $x^{1}=0$ voters updated beliefs according to Bayes' 
Rule are $\mu_{L \mid 0, S^{*}}=\frac{p_{L}}{p_{C}+p_{L}}$ and $\mu_{C \mid 0, S^{*}}=\frac{p_{C}}{p_{C}+p_{L}}$. Thus

$$
\begin{gathered}
E U_{p}(I)=\frac{p_{C}}{4\left(p_{C}+p_{L}\right)}, \quad \text { and } \\
E U_{p}(C h)=-\frac{p_{C}}{4}-p_{R} .
\end{gathered}
$$

This yields $\gamma_{p}(0)=1$ iff

$$
p_{R}>\frac{1}{4}\left(\frac{p_{C}}{p_{C}+p_{L}}-p_{C}\right)
$$

When $x^{1}=1$ is implemented $\mu_{R \mid 1, S^{*}}=1$,

$$
E U_{p}(I)=-1
$$

and $\gamma_{p}(1)=0$.

After observing $x^{1}=\frac{1}{2}$, voters again cannot update their beliefs following Bayes' Rule and I aplly D1. Thus $C$ would find it profitable to deviate to $x^{1}=\frac{1}{2}$ when

$$
\gamma^{C}>\frac{x^{2}-x}{w+\frac{p_{L}}{4}++\frac{p_{R}}{4}}+1
$$

and $R$ would find it profitable to deviate when

$$
\gamma^{R}>\frac{(x-1)^{2}}{w+p_{L}+\frac{p_{C}}{4}}
$$

Whether the deviation is expected to come from $C$ or $R$ depends on the parameter values. Whenever $\mu_{C \mid \frac{1}{2}, S^{*}}=1$, after observing $x^{1}=\frac{1}{2}$ poor voters compare:

$$
E U_{p}(I)=-\frac{1}{4}
$$

to

$$
E U_{p}(C h)=-\frac{p_{C}}{4}-p_{R} .
$$


If poor voters reelect an incumbent who implements $x^{1}=\frac{1}{2}$, then $C$ would deviate. Thus we need $\gamma_{p}\left(\frac{1}{2}\right)=0$ which requires

$$
p_{R}<\frac{1}{4}\left(1-p_{C}\right)
$$

Now, when the deviation is expected to come from $R$, then

$$
E U_{p}(I)=-1
$$

and $\gamma_{p}\left(\frac{1}{2}\right)=0$.

Now we need to consider profitable deviations on the part of candidates. Since under the conditions stipulated so far, $L$ is obtaining her highest possible utility by playing her equilibrium strategies, $L$ will not deviate. Both $C$ and $R$, however, may deviate.

Consider $R$ first. Given voters beliefs any deviation by $R$ results in no-reelection. Of all possible deviations the one bringing highest utility to $R$ is $x^{1}=1$ since utility from office is constant and $x^{1}=1$ maximizes her utility from policy. $R$ 's expected utility from this unilateral deviation, denote it by $s_{R}^{\prime}$, is

$$
E U_{R}\left(s_{R}^{\prime},\left(s_{L}^{*}, s_{C}^{*}\right)\right)=w-\frac{p_{C}}{4}-p_{L}
$$

while

$$
E U_{R}\left(S^{*}\right)=2 w-1
$$

The necessary and sufficient conditions for $R$ not to deviate are given by $E U_{R}\left(S^{*}\right)>E U_{R}\left(s_{R}^{\prime},\left(s_{L}^{*}, s_{C}^{*}\right)\right)$. This yields

$$
w<1-p_{L}-\frac{p_{C}}{4}
$$

Now consider $C$. By the same logic above, the most profitable deviation by $C$ is to $x^{1}=\frac{1}{2}$. $C$ 's 
expected utility from this unilateral deviation, denote it by $s_{C}^{\prime}$, is

$$
E U_{C}\left(s_{C}^{\prime},\left(s_{L}^{*}, s_{R}^{*}\right)\right)=w-\frac{p_{L}}{4}-\frac{p_{R}}{4}
$$

while

$$
E U_{C}\left(S^{*}\right)=2 w-\frac{1}{4}
$$

The necessary and sufficient conditions for $C$ not to deviate are given by $E U_{C}\left(S^{*}\right)>E U_{C}\left(s_{C}^{\prime},\left(s_{L}^{*}, s_{R}^{*}\right)\right)$. This yields

$$
w>\frac{p_{C}}{4} .
$$

Proof of Proposition 3: After observing $x^{1}=0$ voters updated belief according to Bayes' Rule is $\mu_{L \mid 0, S^{*}}=1$. This yields

$$
E U_{p}(I)=0
$$

which poor voters compare to their expected utility from electing the challenger,

$$
E U_{p}(C h)=\frac{3}{4} p_{C}+p_{L}-1
$$

Since $E U_{p}(I)>E U\left(C h \mid S^{*}\right), \gamma_{p}(0)=1$. After observing $x^{1}=1$, voters believe the candidate's type is $R$, that is $\mu_{R \mid 1, S^{*}}=1$. This leads to

$$
E U_{p}(I)=-1
$$

and $\gamma_{p}(1)=0$.

After observing $x^{1}=\frac{1}{2}$ voters updated belief according to Bayes' Rule is $\mu_{C \mid \frac{1}{2}, S^{*}}=1$ and

$$
E U_{p}(I)=-\frac{1}{4}
$$


The poor reelects $C$ iff

$$
p_{L}<\frac{3}{4}\left(1-p_{C}\right)
$$

which is satisfied by $p_{L}<\frac{1-p_{c}}{4}$.

While not relevant for the equilibrium characterized, I discuss other voters equilibrium voting strategies. After observing $x^{1}=\frac{1}{2}, m$ voters get their maximum utility and choose $\gamma_{m}\left(\frac{1}{2}\right)=1$ since $p_{c}<1$. Rich voters choose $\gamma_{r}\left(\frac{1}{2}\right)=1$ if and only if $E U_{r}(I)>E U_{r}(C h)$. This holds only if $p_{L}>\frac{1-p_{c}}{4}$. Since from $w<\frac{1}{4}-\left(p_{L}+\frac{p_{C}}{4}\right)$ it follows that $p_{L}<\frac{1-p_{c}}{4}, \gamma_{r}\left(\frac{1}{2}\right)=0$. After observing $x^{1}=1$ rich voters get their maximum utility and choose $\gamma_{r}(1)=1$ given $p_{R}<1$. $m$ voters are indifferent between $s_{L}^{*}$ and $s_{R}^{*}$. Given that there is a positive probability of the challenger being a centrist candidate, that is $p_{C}>0$, then $E U_{m}(I)<E U_{m}(C h)$, leading to $\gamma_{m}(1)=0$. A similar logic applies to $m$ after she observes $x^{1}=0$, which leads again to $\gamma_{m}(0)=0$.

Now we need to consider profitable deviations on the part of candidates. Since under the conditions stipulated so far both $L$ and $C$ are getting their highest possible utility by playing their equilibrium strategies, they will not deviate. $R$, however, may deviate. A deviation by $R$ to $x_{R}^{1}=0$ yields a strictly lower payoff than a deviation to $x_{R}^{1}=\frac{1}{2}$, since in both cases $R$ gets reelected and the further she moves from her ideal point the lower her payoff. Thus if we show the latter is not profitable, then the former deviation is not profitable either. $R$ 's expected utility from this unilateral deviation, denote it by $s_{R}^{\prime}$, is

$$
E U_{R}\left(s_{R}^{\prime},\left(s_{L}^{*}, s_{C}^{*}\right)\right)=-\frac{1}{4}+2 w
$$

while

$$
E U_{R}\left(S^{*}\right)=w-p_{L}-\frac{p_{C}}{4}
$$

The necessary and sufficient condition for $R$ not deviating is given by $E U_{R}\left(S^{*}\right)>E U_{R}\left(s_{R}^{\prime},\left(s_{L}^{*}, s_{C}^{*}\right)\right)$. 
This yields

$$
\begin{aligned}
w & <\frac{1}{4}-\left(p_{L}+\frac{p_{C}}{4}\right) \quad \text { or } \\
p_{L} & <\frac{1-p_{c}}{4}
\end{aligned}
$$

when $w=0$.

Proof of Uniqueness: Let $\underline{w}^{1}=2-p_{L}-\frac{p_{C}}{4}$ denote the lower bound value of office supporting the equilibrium in Proposition $1, \bar{w}^{2}=1-p_{L}-\frac{p_{C}}{4}$ denote the upper bound value of office supporting the equilibrium in Proposition 2, and $\bar{w}^{3}=\frac{1}{4}-\frac{p_{C}}{4}$ denote the upper bound value of office supporting the equilibrium in Proposition 3. Then $\underline{w}^{1}>\bar{w}^{2}$ and $\underline{w}^{1}>\bar{w}^{3}$. Hence the equilibrium in Proposition 1 is unique.

Now let $\underline{p}_{R}^{3}=\frac{3}{4}\left(1-p_{C}\right)+w$ denote the lower bound probability of a right type supporting the equilibrium in Proposition $3, \bar{p}_{R}^{1}=\frac{1}{4}\left(1-p_{C}\right)$ denote the upper bound probability of a right type supporting the equilibrium in Proposition 1 and 2. Given ${\underline{p_{R}}}^{3}>\bar{p}_{R}^{1}$ the equilibrium in Proposition 3 is unique, and consequently the equilibrium in Proposition 2.

\section{Proof of non-existence of additional pure strategy equilibria:}

First I show that no pure strategy equilibrium exists where $x_{L}^{1} \neq 0$. Second I show that no pure strategy equilibrium exists where $x_{C}^{1}=1$. And finally I show the remaining three possible sets of pure strategies are not a Perfect Bayesian Equilibrium.

I show that $x_{L}^{1}=0$ by contradiction. Suppose first that $x_{L}^{1}=1$. Then either:

a) $x_{L}^{1}=x_{C}^{1}=x_{R}^{1}=1 \Rightarrow \Gamma(1)=\frac{1}{2}$. By D1 $\mu_{L \mid 0}=1 \Rightarrow \gamma_{p}(0)=1$. Thus $L$ deviates.

b) $x_{L}^{1} \neq x_{C}^{1}$ and $x_{L}^{1} \neq x_{R}^{1} \Rightarrow \mu_{L \mid 1}=1 \Rightarrow \gamma_{p}(1)=1$. Thus $R$ deviates

c) $x_{L}^{1}=x_{R}^{1} \neq x_{C}^{1}$. In this case $\mu_{L \mid 1}=\frac{p_{L}}{p_{L}+p_{R}}$ and $\mu_{R \mid 1}=\frac{p_{R}}{p_{L}+p_{R}}$. If $\gamma_{p}(1)=0$ then $L$ deviates. If $\gamma_{p}(1)=\frac{1}{2}$, then $p_{R}=\frac{1}{4}-\frac{p_{C}}{4}$, leading to $\gamma_{r}(1)=0$. Since $\gamma_{m}(1)=0, \Gamma(1)=0$, and $L$ deviates. 
Finally, If $\gamma_{p}(1)=1$ then $p_{R}<\frac{1}{4}\left(1-p_{C}\right)$ and $\gamma_{p}\left(x_{C}^{1}\right)=0$. If $x_{C}^{1}=0$ then $C$ deviates to $x_{C}^{1}=\tilde{x}_{C}=\frac{1}{2}$. If $x_{C}^{1}=\frac{1}{2}$ then the condition for $C$ not deviating to $x \in\{0,1\}$ is $w<1-\frac{p_{C}}{2}$. Given $\gamma_{p}\left(\frac{1}{2}\right)=0$, the most profitable deviation for $L$ is to $x=0$ and the condition for that not to happen is $w>1-\frac{p_{C}}{4}-p_{R}$. The only way both these conditions can be met is when $p_{R}>1-\frac{p_{C}}{2}$ which contradicts $p_{R}<\frac{1}{4}\left(1-p_{C}\right)$.

d) $x_{L}^{1}=x_{C}^{1} \neq x_{R}^{1}$. Let $x_{R}^{1}=x^{\prime}$, where $x^{\prime} \in\left\{0, \frac{1}{2}\right\}$. Then $\mu_{R \mid x^{\prime}}=1$ and $\gamma_{p}\left(x^{\prime}\right)=0$. Thus $R$ deviates.

Now suppose $x_{L}^{1}=\frac{1}{2}$. Then either:

a) $x_{L}^{1}=x_{C}^{1}=x_{R}^{1}=\frac{1}{2} \Rightarrow \Gamma\left(\frac{1}{2}\right)=\frac{1}{2}$. By D1 $\mu_{L \mid 0}=1 \Rightarrow \gamma_{p}(0)=1$. Thus $L$ deviates.

b) $x_{L}^{1} \neq x_{C}^{1}$ and $x_{L}^{1} \neq x_{R}^{1} \Rightarrow \mu_{L \mid \frac{1}{2}}=1 \Rightarrow \gamma_{p}\left(\frac{1}{2}\right)=1$. Thus $C$ deviates

c) $x_{L}^{1}=x_{R}^{1} \neq x_{C}^{1}$. If $\gamma_{p}\left(\frac{1}{2}\right)=1$ then $C$ deviates. If $\gamma_{p}\left(\frac{1}{2}\right)=0$, then both $L$ and $R$ deviate. If $\gamma_{p}\left(\frac{1}{2}\right)=\frac{1}{2}$, then $p_{R}=\frac{1}{4}\left(1-p_{C}\right) \Rightarrow \gamma_{r}\left(\frac{1}{2}\right)=0$. Given $\gamma_{m}\left(\frac{1}{2}\right)=0$ we have $\Gamma\left(\frac{1}{2}\right)=0$, thus both $L$ and $R$ deviate.

d) $x_{L}^{1}=x_{C}^{1} \neq x_{R}^{1}$. By D1, $L$ would deviate to $x^{1}=0$ for any $\gamma>\frac{1}{2}-\frac{1}{4\left(w+\frac{p_{C}}{4}+p_{R}\right)}$ while $C$ for any $\gamma>\frac{1}{2}+\frac{1}{4\left(w+\frac{p_{C}}{4}+\frac{p_{R}}{4}\right)}$. Thus $\mu_{L \mid 0}=1 \Rightarrow \gamma_{p}(0)=1$ and $L$ deviates.

Next I show that $x_{C}^{1} \neq 1$ by contradiction. Suppose that $x_{C}^{1}=1$. Then either:

a) $x_{C}^{1}=x_{R}^{1}=1$. Then $\mu_{C \mid 1}=\frac{p_{C}}{p_{C}+p_{R}}$ and $\mu_{R \mid 1}=\frac{p_{R}}{p_{C}+p_{R}}$ leading to $\gamma_{p}(1)=0$. Hence $C$ deviates.

b) $x_{C}^{1} \neq x_{R}^{1}=1$. Then $\mu_{C \mid 1}=1$. If $\gamma_{p}(1)=1$, then $R$ deviates. If $\gamma_{p}(1)=0$, then $C$ deviates. If $\gamma_{p}(1)=\frac{1}{2}$, then $p_{R}=\frac{1}{4}\left(1-p_{C}\right)$ which leads to $\gamma_{R}(1)=1$. Since $\gamma_{m}(1)=1$, then $\Gamma(1)=1$ and $R$ deviates.

Finally I need to show the remaining three possible combinations of pure strategies are not an equilibrium.

If $S^{*}=\left(\left(x_{L}^{1}=0, x_{L}^{2}=0\right),\left(x_{C}^{1}=0, x_{C}^{2}=\frac{1}{2}\right),\left(x_{R}^{1}=\frac{1}{2}, x_{R}^{2}=1\right)\right), \gamma_{p}\left(\frac{1}{2}\right)=0$, since $\mu_{R \mid \frac{1}{2}, S^{*}}=1$, and $E U_{R}\left((1,1),\left(s_{L}^{*}, s_{C}^{*}\right)\right)>E U_{R}\left(S^{*}\right)$. Thus $R$ deviates.

If $S^{*}=\left(\left(x_{L}^{1}=0, x_{L}^{2}=0\right),\left(x_{C}^{1}=\frac{1}{2}, x_{C}^{2}=\frac{1}{2}\right),\left(x_{R}^{1}=\frac{1}{2}, x_{R}^{2}=1\right)\right)$, then $\mu_{C \mid \frac{1}{2}, S^{*}}=\frac{p_{C}}{p_{C}+p_{R}}, \mu_{R \mid \frac{1}{2}, S^{*}}=$ $\frac{p_{R}}{p_{C}+p_{R}}$ and $E U_{p}\left(I \mid x^{1}=\frac{1}{2}\right)<E U_{p}(C h)$, yielding $\gamma_{p}\left(\frac{1}{2}\right)=0$. This means $E U_{R}\left((1,1),\left(s_{L}^{*}, s_{C}^{*}\right)\right)>$ 
$E U_{R}\left(S^{*}\right)$, thus $R$ deviates.

If $S^{*}=\left(\left(x_{L}^{1}=0, x_{L}^{2}=0\right),\left(x_{C}^{1}=\frac{1}{2}, x_{C}^{2}=\frac{1}{2}\right),\left(x_{R}^{1}=0, x_{R}^{2}=1\right)\right)$, then $\mu_{C \mid \frac{1}{2}, S^{*}}=1, \mu_{L \mid 0, S^{*}}=\frac{p_{L}}{p_{L}+p_{R}}$, $\mu_{R \mid 0, S^{*}}=\frac{p_{R}}{p_{L}+p_{R}}$. Thus $\gamma_{p}(0)=1$ iff $p_{C}>4 \frac{p_{R}}{p_{L}+p_{R}}-4 p_{R}$ and $\gamma_{p}\left(\frac{1}{2}\right)=0$ iff $p_{C}<1-4 p_{R}$. That is, either $\gamma_{p}(0)=\gamma_{p}\left(\frac{1}{2}\right)=1$ or $\gamma_{p}(0)=\gamma_{p}\left(\frac{1}{2}\right)=0$. In the first case $E U_{R}\left((1,1), S_{-R}^{*}\right)>E U_{R}\left(S^{*}\right)$ and in the second $E U_{R}\left(\left(\frac{1}{2}, 1\right), S_{-R}^{*}\right)>E U_{R}\left(S^{*}\right)$. Hence in both cases $R$ deviates.

The proofs of Propositions 5 to 9 follow closely from the proofs just shown. In Proposition 5 a substitutes $\frac{1}{2}$ and in propositions 6 to 9 utilities are not quadratic, but expressed in terms of absolute values instead.

Proof of Proposition 9: Since all types choose the same policy in the first period, no updating occurs and $\gamma_{p}(0)=\gamma_{m}(0)=\gamma_{r}(0)=\frac{1}{2}$. The condition for $\mu_{R \mid\{b, 0\}}=1$ is derived from application of the divinity refinement as follows:

$$
\begin{aligned}
E U_{R}\left(s_{R}^{\prime},\left(s_{L}^{*}, s_{C}^{*}\right)\right) & >E U_{R}\left(S^{*}\right) \\
\gamma^{R} & >\underbrace{\frac{b^{2}-1}{w+(1-b)^{2} p_{C}+p_{L}}+\frac{1}{2}}_{a(x)} \\
E U_{C}\left(s_{C}^{\prime},\left(s_{R}^{*}, s_{L}^{*}\right)\right) & >E U_{C}\left(S^{*}\right) \\
\gamma^{L} & >\underbrace{\frac{-b^{2}}{w+b^{2} p_{L}+(1-b)^{2} p_{R}}+\frac{1}{2}}_{c(x)}
\end{aligned}
$$

$\mu_{R \mid\{b, 0\}}=1$ iff $a<c$, which yields

$$
p_{C}<\frac{w\left(1-2 b^{2}\right)-b^{4}+p_{R}\left(1+2 b^{3}-2 b\right)}{b^{2}-2 b^{3}}
$$


The condition for $R$ not deviating is $p_{C}>\frac{2-w-p_{L}}{(1-b)^{2}}$ which also guarantees $C$ does not deviate.

Proof of Proposition 10: After observing $x^{1}=0, \mu_{L \mid 0}=1$ and $\gamma_{p}(0)=1$ iff $p_{L}>1-\frac{(1-b)^{2}}{b^{2}}$. Given that $b<\frac{1}{2}, \gamma_{p}(1)=0$. The condition for $R$ not deviating is given by $E U_{R}\left(S^{*}\right)>$ $E U_{R}\left((b, 1), S_{-R}^{*}\right)$, which is $p_{L}<(1-b)^{2}\left(1-p_{C}\right)-w$.

Proof of non-existence of additional equilibria where $s_{L}=(0,0)$ and $\gamma_{P}(0)=1$ when $\tilde{x}_{p}=\tilde{x}_{m}=\tilde{x}_{C}=b$ : Four possible cases need to be considered:

a) If $S^{*}=\left(\left(x_{L}^{1}=0, x_{L}^{2}=0\right),\left(x_{C}^{1}=0, x_{C}^{2}=b\right),\left(x_{R}^{1}=b, x_{R}^{2}=1\right)\right)$, then $\mu_{R \mid b}=1 \Rightarrow \gamma_{p}(b)=0$ and $R$ deviates.

b) If $S^{*}=\left(\left(x_{L}^{1}=0, x_{L}^{2}=0\right),\left(x_{C}^{1}=b, x_{C}^{2}=b\right),\left(x_{R}^{1}=0, x_{R}^{2}=1\right)\right)$, then $\mu_{C \mid b}=1 \Rightarrow \gamma_{p}(b)=1$ and $R$ deviates.

c) If $S^{*}=\left(\left(x_{L}^{1}=0, x_{L}^{2}=0\right),\left(x_{C}^{1}=1, x_{C}^{2}=b\right),\left(x_{R}^{1}=0, x_{R}^{2}=1\right)\right)$, then $\mu_{C \mid 1}=1 \Rightarrow \gamma_{p}(1)=1$ and $R$ deviates.

d) If $S^{*}=\left(\left(x_{L}^{1}=0, x_{L}^{2}=0\right),\left(x_{C}^{1}=0, x_{C}^{2}=b\right),\left(x_{R}^{1}=1, x_{R}^{2}=1\right)\right)$ then $\gamma_{p}(0)=1$ iff $p_{L}>\frac{(1-b)^{2}}{b^{2}}(1-$ $p_{R}$ ). If $\mu_{C \mid b}=1$, then $C$ deviates. If $\mu_{R \mid b}=1$ then, following the divinity refinement, it must be the case that $a<c$, where $a$ and $c$ are as follows:

$$
\begin{aligned}
E U_{R}\left(s_{R}^{\prime},\left(s_{L}^{*}, s_{C}^{*}\right)\right) & >E U_{R}\left(S^{*}\right) \\
\gamma^{R} & >\underbrace{\frac{(1-b)^{2}}{w+(1-b)^{2} p_{C}+p_{L}}+\frac{1}{2}}_{a(x)}
\end{aligned}
$$




$$
\begin{aligned}
E U_{C}\left(s_{C}^{\prime},\left(s_{R}^{*}, s_{L}^{*}\right)\right) & >E U_{C}\left(S^{*}\right) \\
\gamma^{L} & >\underbrace{1-\frac{-b^{2}}{w+b^{2} p_{L}+(1-b)^{2} p_{R}}+\frac{1}{2}}_{c(x)}
\end{aligned}
$$

When $p_{L}>\frac{(1-b)^{2}}{b^{2}}\left(1-p_{R}\right)$, however, $a(x)>c(x)$, thus $\mu_{C \mid b}=1$ and $C$ deviates.

\subsection{Beta Distribution Model}

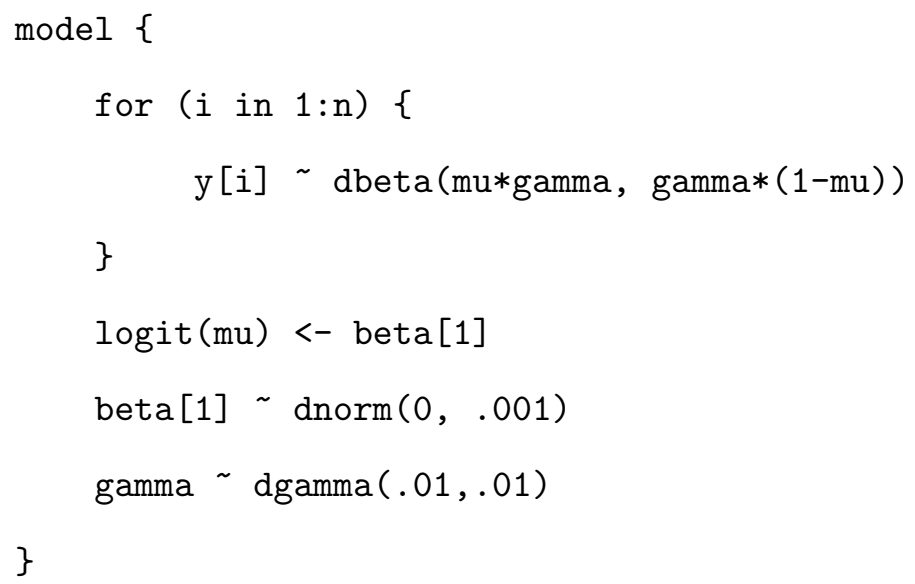

